\title{
Electronic-Customer Complaint Management System (E-CCMS) - a Generic Approach
}

\author{
Esraa A. Afify \\ Faculty of Computers \& Information, Information Systems Department, Helwan University, Cairo, Egypt. \\ Esraa_Afify@hotmail.com \\ Mona A. Kadry \\ College of Computing and Information Technology, Arab Academy for Science, Technology \& Maritime Transport, \\ Cairo, Egypt. \\ Monakadry@aast.edu
}

\begin{abstract}
-ABSTRACT-
Customer Complaints are considered vital and significant information that can be utilized to attain customers' satisfaction. Consequently, establishing a complaint handling system is essential towards addressing customer dissatisfaction and preventing similar problems from reoccurring. The main objective of this paper is to investigate the degree of association between customers' complaint behaviors and their complaints about the goods or services they get. Therefore, the paper proposes a generic approach for the Customer Complaint Management System that can be effective in reducing customers' complaints through urging customers to participate in controlling the quality of the services or goods offered to them. The "Service" has been used to connect different databases from different platforms to retrieve certain data. The system starts by discussing the service implementation with the web-application interface development. Afterward, the "Service" is used to connect the three main Services used in the proposed e-complaint web service. These services have been explored to obtain the Citizen and Staff data and find out about how they are working. Then, they have been implemented in the web application, each according to the operation that calls the service to restore certain data. Moreover, the most important reports extracted from the evaluation results have also been explored. For implementing the model, a web application has been developed to exhibit both the ability of the model and the efficiency in e-Gov, since that web application could be developed thoroughly. It was supposed that to complete the e-complaint system cycle, there is a need for five modules to implement this cycle; the first module is related to the "Citizen" who wants to fill his/her complaint; the second is the "Admin" who manages the system users; the third is the "Agent" who will handle the Citizen complaints; the fourth is the "Staff" who will analyze the causes and actions of each complaint; and the fifth module is the "Supervisor" who views the overviews reports and takes decisions for improvements.
\end{abstract}

Keywords - Complaint Handling System, Complaint Management System, e-Complaint, SOA.

Date of Submission: July 22, 2019

Date of Acceptance: Aug 24, 2019

\section{INTRODUCTION}

In nowadays market, the internet is increasingly used in many different areas; we can see various services being offered through the IT environment. Utilizing websites as a tool for interaction is something greatly beneficial to both providers and users. From Users' point of view, first, the IT environment makes it easy for them to access; wherever they are they can access the internet to invoke services. Second, it facilitates the process of reacting; if a website interface is user-friendly, users can easily and quickly interact and find the services which they are looking for. Finally using the IT environment is timesaving since users don't need to refer to the providers directly. From the Providers' point of view, web-based tools are time and money saving, and they greatly facilitate offering new products /services as well as contacting and announcing clients.

The evolution of web-applications such as Portals is increasing with the continuous improvements in the appearance of recent requisites and characteristics. Accordingly, promoting "Web Services" through utilizing the "Service-Oriented Architecture" pattern is a commonly another point. On the other side, most of the users' dissatisfactions are evident when a system has improper contact among firms, their jobholders, and clients (Citizens). Improper communication usually leads to offering lowquality services or goods by the firm or government. Any organization can reach an efficient success factor by raising the user's satisfaction when focusing on the matter of complaint handling. Hence, to achieve business growth, producers need to have highly developed internal and external communication among their employees and consumers. An excellent communication is supposed to minimize customers' dissatisfaction to a great extent, but, unfortunately, it cannot do away with the complaint.

Complaints normally embody all about life items and services which we have either used or bought such as food products, friends, careers, housing, public transportation facilities, and weather forecasting. Dissatisfaction has always been part of human nature that some consumers are very skilled when it comes to ways of complaining. Yet, most manufacturers are not very experienced in dealing with customers' complaints and suggestions. Occasionally, some producers belittle customers' complaints and look upon them as a trivial issue too hard to be managed. 
Efficient managing of complaints is the ability to be attained and enhanced through training and learning. Thus, training a business firm employee to effectively cope with buyers' complaints is something vital towards giving an excellent service or product to consumers, thereby helping the firm to gain both a good profit and reputation. Considering this, this paper lays emphasis on the governmental services context in managing complaint.

Paper Outline. The paper is organized as follows: Section II gives a brief synopsis of the existing work concerning the problem under study. Section III provides the proposed model structure. Section IV explains the system analysis. Section V illustrates the system design. Section VI explores the system implementation. Finally, section VII concludes the research under study.

\section{LITERATURE REVIEW}

A previous related most recent research paper has been recently conducted on student complaint, it is Afify, et al. (2017) [2]. The paper presents a generic automated mechanism technique suitable for providing academic advising in the university system. It proposes a new model for e-Academic Advising System as a web-based application. The researchers have created a system which helps the academic advisors to successfully provide their students with whatever necessary advice. The system can easily investigate the design and implementation of a computerized tool to ease this operation. The proposed model has resulted in a model that enables both the staff and advisor to access so that they can make a follow-up of the students' complaints and their proposals and comments. Also, the model enables the students to raise their complaints and submit their propositions in whatever subjects. Eventually, the model supports department heads in running their departments efficiently through the KPIs reports they get.

Also, the researchers have proposed that Afify, et al. (2011) [1], is highly related to the research topic as it presents a new model of e-Complaint web service based on Service-Oriented Architecture (SOA). In this model, the researchers have tried to regain the connection between Citizens and Social Solidarity. The proposed model aims to create a Web-based e-Complaint related to the subsidiary lifecycle. The cycle begins with the distribution of various services supplied through the subsidiary. Those services were delivered to various people according to their requirements. Due to different hindrances, those services may not be efficiently applied. Because of that, there has been a must for a system that tracks down and discovers Citizens problems and provides them with suitable feedback. This system can manage complaints through recording them and giving feedback for each raised complaint. The study outcome has been a helpful reference to determine users' requirements from the e-Complaint and the managing process of this complaint in the core of any firm.

Razali, et al. (2011) [11], have established a novel complaint managing system. The manual managing process of complaint among customers and the university staff has been exploited to create the new complaint handling system. A novel complaint handling system called e-Aduan has been made. Both customers and management staff have had access to the new system to complain and get feedback. In this study, the researchers have also specified workflow procedures so that they can be adopted by the management staff to handle customers' complaints and comments. This new technique is beneficial to both customers and management staff; customers now have a platform to express their dissatisfactions and the staff would be able to react simultaneously upon customers' feedback.

Pyon, et al. (2011) [10], have thought that customer complaints by call centers are enough to support the analysis of service promotion in the monetary service industry. Thus, they have proposed a web-based decision support system for running the business operation exploiting customer complaints; Voice of the Customer (VOC). The system has been tackling information for service promotion and involving VOC conversion for information upgrading together with including analysis of outlining, exception, and comparisons.

Najar, et al. (2010) [9], have attempted to promote the relationship between citizens and government by offering a novel model based on Service-Oriented Architecture (SOA). The established model in the governmental sector, serves both to enable the governments to reduce citizens' complaints to the minimum and to urge citizens to take part in controlling government body like governments' employees and firms.

Trappey, et al. (2010) [13], have analyzed the configuration of the complaint handling system for a restaurant chain in Japan. The complaint handling process gets over the defective approach of prior complaint handling through modifying the operations. So, this was beneficial to the operations taking place between the chain main administrative center and the other branches. To describe the complaint handling model and its process, the formal integrated process modelling (INCOME) approach has been utilized. The new configuration contained complaint reporting, compensation diagnosis as well as complaint analysis. Moreover, the model, through the system, can spontaneously give the decision support on complaint resolution.

Hansen, et al. (2010) [7], have used the cluster analysis to pinpoint two clusters of retailers, based on the degree of their activity in complaint handling. They are either nonactive or medium-active complaint handlers. The complaint handlers have assumed that complaint handling is strategically more relevant for the medium-active handlers than for the non-active ones. Furthermore, the mediumactive complaint handlers tend more to recompense the complainers for their losses. The study results have shown that retailers usually disparage customers from raising complaints.

Breitsohl, et al. (2010) [4], have introduced a hypothesis of credibility and conformity in behaviour orientation which expanded the understanding of complaints and appraisals of complaint conversation. The study states that foretold outcomes for both the online complaint image and relationship management together with utilizing credibility serve as a criterion for online customer contentment.

Galitsky, et al. (2009) [6], have proposed a new way for modelling and sorting complaint scenarios connected with customer-firm conversations. These conversations were designed as tagged graphs, where the firm and client can communicate to exchange and transport their viewpoints.

$\mathrm{Au}$, et al. (2009) [3], have investigated nine complaint types of Hong Kong's Hotel across various bases of the complaints. The study results have shown that although no considerable link was detected between e-complaint types and hotel class, the age group of reviewers is considerably 
linked with certain types of internet complaints. The authors have introduced several types of management reactions against all e-complaint types to recommend the administrator responses.

Vos, et al. (2008) [14], have emphasized the significance of complaint handling as a source of learning. Until recently, the notion of organizational learning has not yet been introduced into the area of complaint handling. Consequently, a study has been conducted to adapt a model for organizational learning to the concept of complaint handling. The study results have shown that a multiplicity of complaint handling practices can be classified along two main constituents which are Informational Learning or Interactive Learning. These practices serve as guidance for upgrading the learning processes through complaints.

Kopparapu, (2008) [8], has presented a natural English mobile interface that could be utilized to file complaints. The goal was to make use of the available web portal framework and provide an immediate complaint registration. The system has helped citizens to file the complaint and try to get recompense by means of their mobile telephone through natural language.

Coussement, \& Van den Poel, (2008) [5], have proposed a technique for promoting complaint handling schemes by means of an automatic email categorization system which separates complaints from non-complaints. Therefore, complaint managing has no longer become timewasting. Moreover, the process has become more successful. The categorization system intermixes traditional text data with new data pertaining to the linguistic style of an e-mail.

Sultan, et al. (2008) [12], have developed an Agentbased Complaint Management system (ACM) run by web application called e-Complaint for students and teaching staff of the Faculty of Science Computer and Information System. Students could make complaints about their discontentment with their faculty. This system was capable of simultaneously registering every single complaint and providing feedback. This was due to upgrading the current (CMS) with the software agent. The software agent that was utilized as an operator assistant to transport the emails to the complaint managing department. This ACM could recognize the complaint manager to whom the complaint would be forwarded with the least human interference through library keyword recognition.

\section{PROPOSED MODEL STRUCTURE}

In this section, the researchers have attempted to develop a model suitable to deal with e-complaints and capable of ridding the complaining process of drawbacks regarding poor service quality and delivery.

After a series of reviews on available research methodologies, the researchers have found WSDM (Web Site Design Method) as an appropriate model for designing e-Complaint web service in terms of an e-Complaint model based on SOA. The research simplifies the idea for some parts of the services; webpage design Rational Unified Process (RUP) was utilized as a guide for how to effectively use the Unified Modeling Language (UML) in research.

The advantage from this proposed model is the easy way of managing the Citizen's complaints about what displeases them. For that, the novel Complaint Management System is essential to get better workflows and make all departments take part in handling the Citizens' complaints.

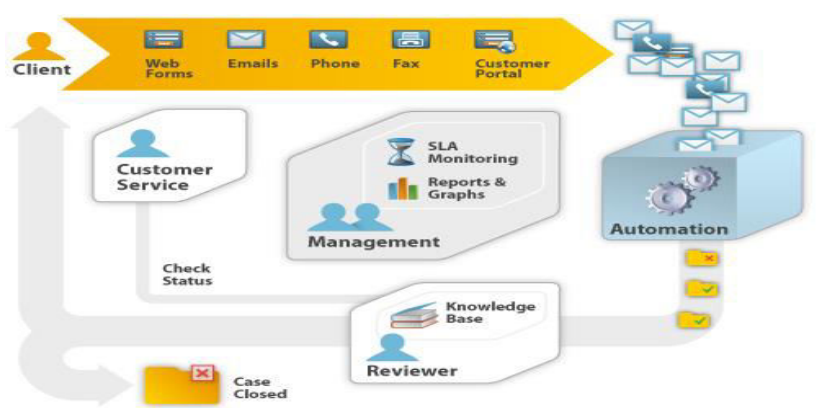

Figure 1: Conceptual Framework.

The coming sections will describe, illustrate and explain the main processes and modules of the system then show how each user will interact in the system according to their roles in the overall cycle of the e-Complaint Management System.

\section{SYSTEM ANALYSIS}

In this section, the researchers give an exposition of the developed model workflow procedure to explore how the system functions. The workflow complaint handling model serves as a platform designed to secure proper and efficient complaint management.

Fig.2 illustrates the chief process as included in the complaint managing model.

- Confirm Citizen authenticity,

- Create the Citizen complaint,

- Classify the complaint according to its priority,

- Search in the knowledge base for an identical situation to get an immediate solution,

- Assign a complaint to the concerned employees who will pinpoint the guidelines on how to track down and settle the complaint cases.

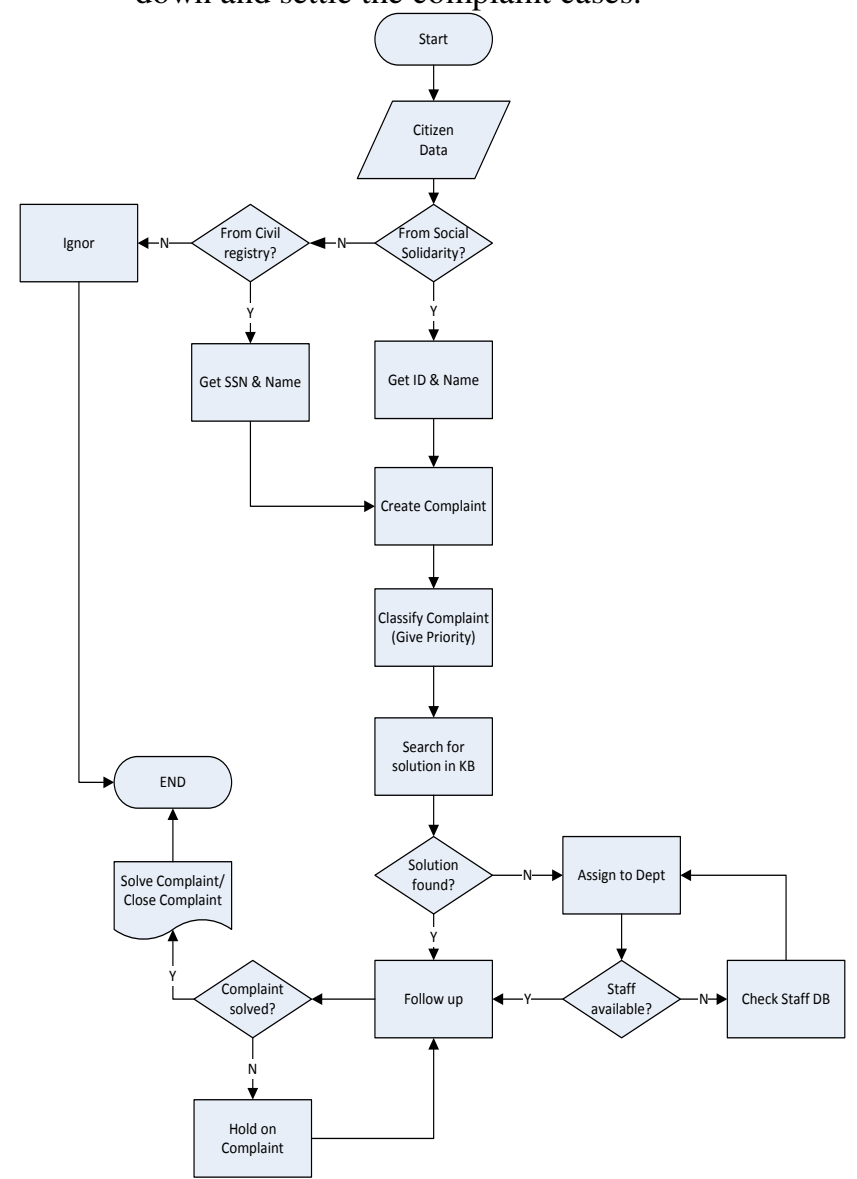

Figure 2: Proposed Workflow Process [1]. 


\section{SYSTEM DESIGN}

This section explains how the system has been designed. The system design phase is considered as a method used to realize the system elements such as the architecture, modules, components as well as the various interfaces of those components and the data that goes through that system. Its purpose is to satisfy the specific needs and requirements needed for a business or an organization through the coherent and well-running system.

\section{1) System Architecture}

To make the model equipped for handling complaint, the researchers have divided the proposed model into 3-tiers as shown in table 1:

Table 1: Proposed Model Tiers [1].

\begin{tabular}{|l|l|}
\hline Tiers & Description \\
\hline Storage - tier & $\begin{array}{l}\text { It includes information pertaining to those who } \\
\text { use the system, their profiles, Citizens } \\
\text { information available resources in addition to } \\
\text { social association profiles. }\end{array}$ \\
\hline Business - tier & $\begin{array}{l}\text { It is composed of the system key part that } \\
\text { includes complaint handling and feedback } \\
\text { components. }\end{array}$ \\
\hline Presentation - tier & It comprises web-based user interface. \\
\hline
\end{tabular}

Fig.3. illustrates the proposed layered SOA architecture that consists of three tiers each tier serves a certain task.

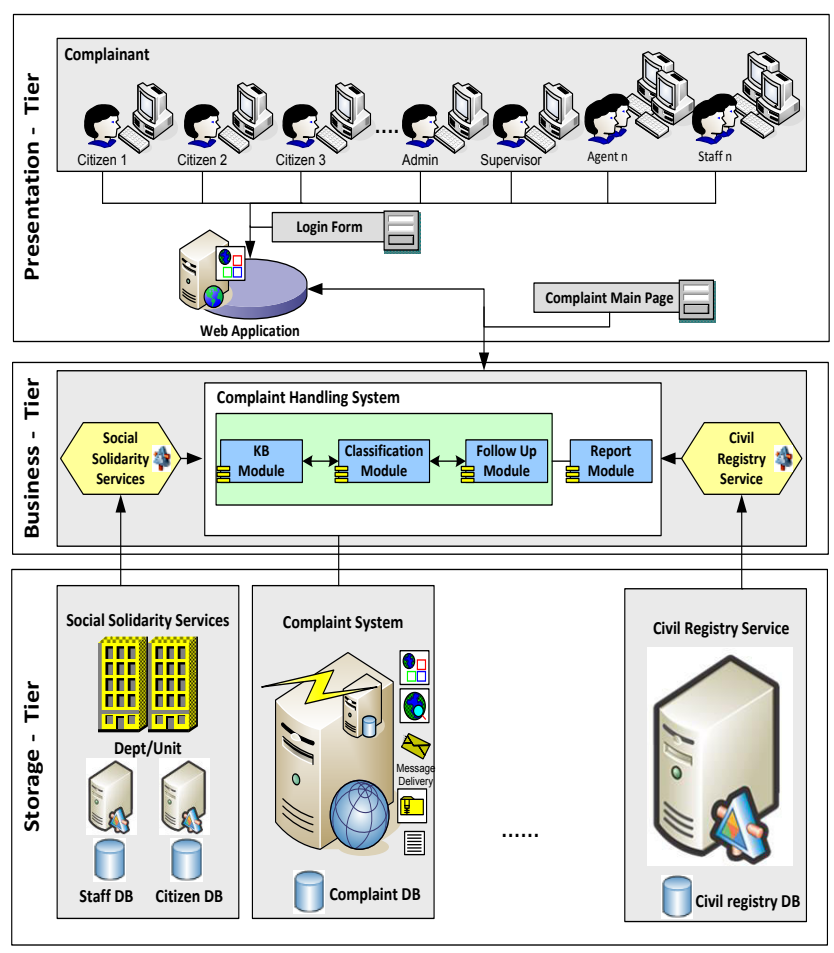

Figure 3: Proposed Model Architecture.

\section{2) Implementation Design}

Having exposed the proposed model architecture, the following procedure is the implementation design of the system. In this phase, the researchers have attempted to design an appropriate web application for Citizens Complaints purpose in terms of service complaints. Therefore, this phase starts with using the case diagram and continues with sequence diagram then ends with a class diagram.

\section{A. Use Case Diagram}

In Use Case diagram we have eight-actors divided into two types; first, the main users on the proposed system, and, second, the services available, as shown in table 2 and fig. 4 . Both types interact within the system's boundary, as shown in fig.5.

\section{Scenario Overview}

When a Citizen has an issue with the Social Solidarity the next steps need to be followed:

- A Citizen login to the web and writes in his/ her complaint or communicates with the Agent and report the issue.

- The Agent enrolls the complaint case through opening the complaint system and recording the complaint data.

- The concerned Staff handle the complaints and send them to the responsible employees.

- Complaints are tackled in different departments based on management regulations and guidelines. Then, complaint actions and causes are investigated to attain results in light of which suitable solutions for the complainer's problem could be reached. In case the complainer accepts the proposed solutions, the complaint form is closed. If not, then in charge of department updates, the operation starts over once more with the same complaint.

- The top managing staff can take out KPIs (Key Performance Indicators) reports and investigate them for upgrading the provided services and handling methods, to help in decision making in view of the analysis made by the staffs of the service department.

\section{Roles}

TABLE 2: ROLES FOR ACTORS IN THE PROPOSED MODEL [1].

\begin{tabular}{|l|l|}
\hline Actors & Description \\
\hline Admin & $\begin{array}{l}\text { Create system users, manage their privileges, } \\
\text { manage lookups in SYSDB and manage site } \\
\text { survey. }\end{array}$ \\
\hline Citizen & Make Complaints against the provided services. \\
\hline Agent & $\begin{array}{l}\text { Register the Complaint in the web-based and } \\
\text { after that, update complaint in accordance with } \\
\text { solving procedure. }\end{array}$ \\
\hline Staff & $\begin{array}{l}\text { Handle the Complaints causes and actions in the } \\
\text { system and offer answers. }\end{array}$ \\
\hline Supervisor & $\begin{array}{l}\text { Examines the provided promoting services } \\
\text { reports that can help in decision making. }\end{array}$ \\
\hline Civil registry & Includes all of the citizens' SSN, Name... etc. \\
\hline Social Solidarity & $\begin{array}{l}\text { Holds Citizens' details that are worthy of } \\
\text { service. }\end{array}$ \\
\hline Staff Data & $\begin{array}{l}\text { Comprises the details of all social Solidarity } \\
\text { employees who could be tasked with complaint } \\
\text { handling. }\end{array}$ \\
\hline
\end{tabular}

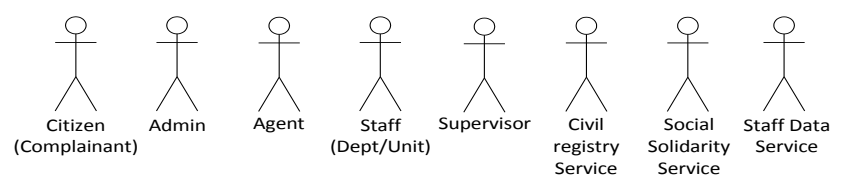

Figure 4: Roles Illustration. 


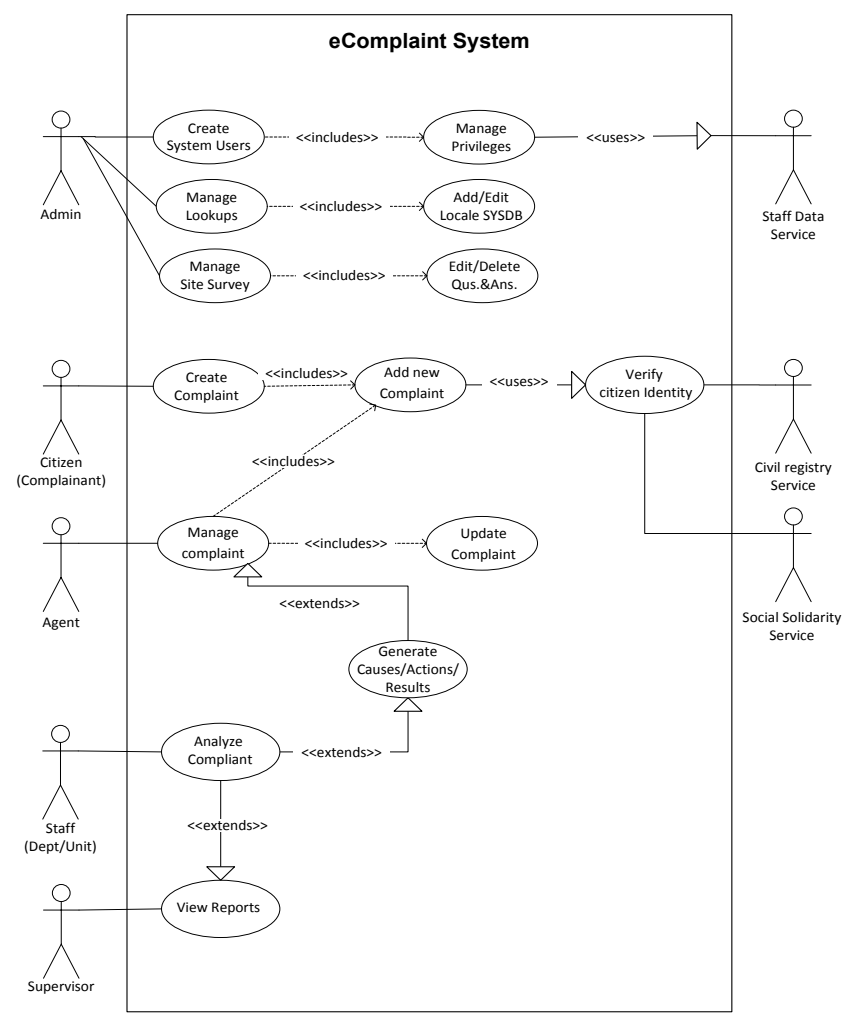

Figure 5: Proposed Use Case Diagram.

\section{B. Sequence Diagram}

In this subsection, the researchers summarize the system's key functions flow by exploiting the sequence diagram to better understand the way the processes run together and the order of their running. This system aims mainly to identify the coming divisions: the system users, the system manager, tasks assignment, created users' complaint, all complaint handling standards, complaint resolution, and all complaints follow-up.

- First user: The Citizen who raises a complaint, as shown in fig.6.

- Second user: The Administrator whose task is to manage the local system DB and to assign the users' tasks, as shown in fig.7.

- Third user: The Agent who enrolls and manages Citizen's Complaints by priority classification and then follows up by searching the knowledge base for solutions; If a solution couldn't be found, he/she submits the complaint to the concerned employees of the service department for handling, as shown in fig.8.

- Fourth user: The Staff in charge of the service department whose task is to handle the failing complaints by describing and dissecting their causes and actions. After that, they resolve the complaints in view of the management rules and offer protective measures lest these complaints should fail any more. Eventually, the staff transfers the complaint cases back to the agent to track them down. The agent then either makes an update of the complaint status or closes it if the problem is solved, as shown in fig.9.

- Fifth user: The Supervisor who takes decisions in view of the KPIs reports, as shown in fig. 10.
Additionally, there are other three key services integrating with the system. They are:

- First service: The Social Solidarity service which comprises all the Citizens' data that make them worthy of getting the services, based on the citizen's region and governorate.

- Second service: The Civil Registry service that includes all the Citizens' personal data, whether they are worthy of getting services. This service also serves to ratify the identity of the complaining Citizen to upgrade the offered services.

- Third service: The staff service which embodies the whole staffs' data, based on the staff's department and the role each of them is assigned to do.

The following diagrams illustrate the flow for the five chief system users and how they integrate with the three services for calling required data.

\section{1) Citizen Sequence diagram:}

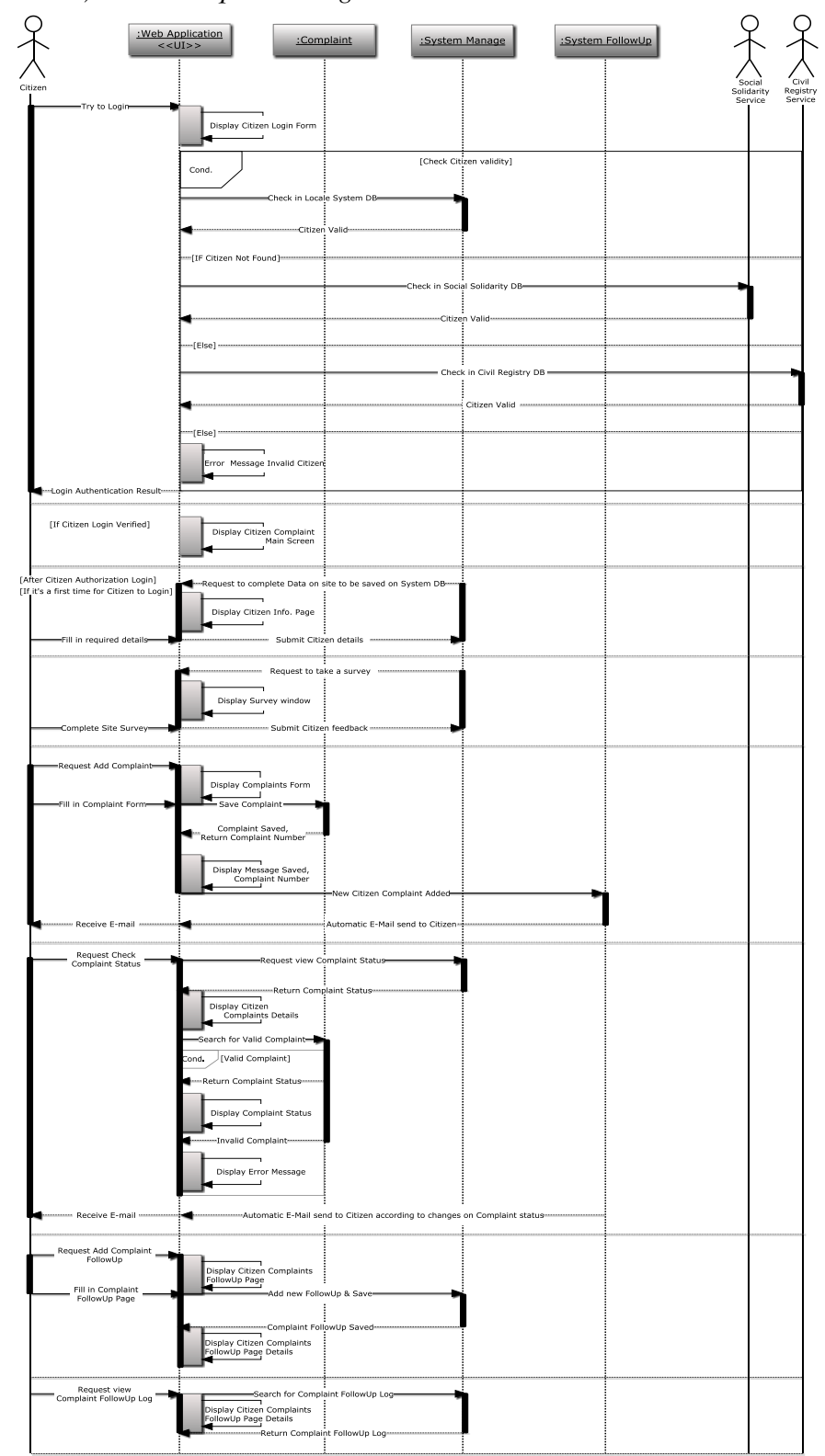

Figure 6: Citizen Sequence Diagram for the Proposed System. 
Volume: 11 Issue: 01 Pages: 4125-4141 (2019) ISSN: 0975-0290

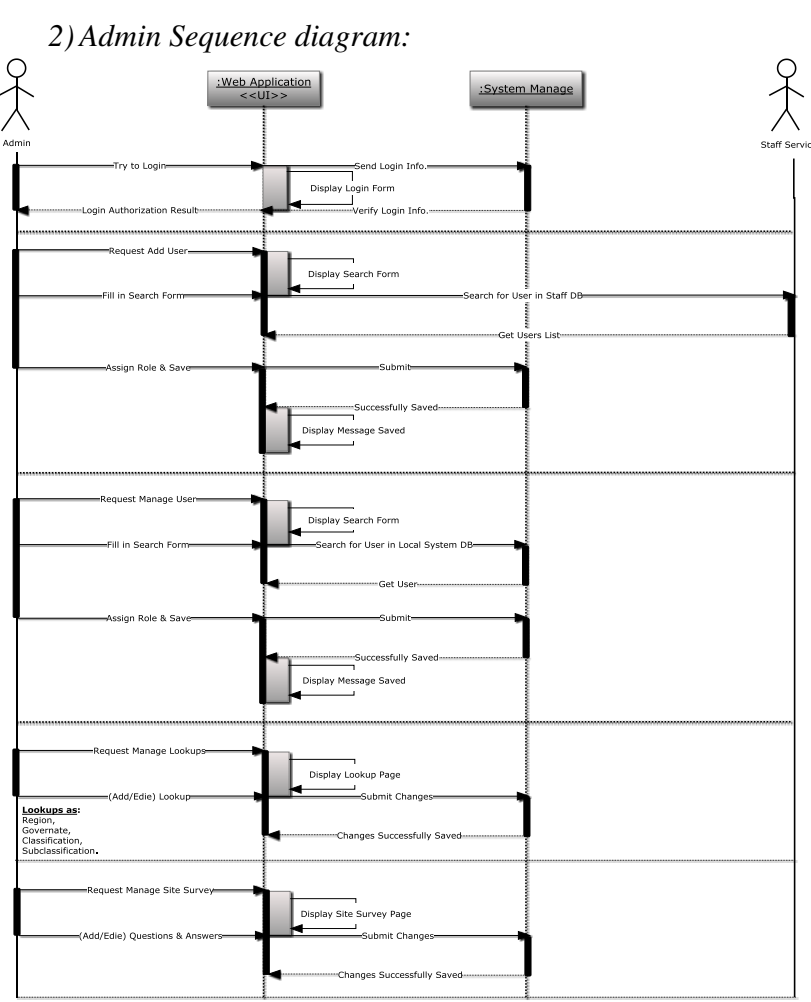

Figure 7: Admin Sequence Diagram for the Proposed System.

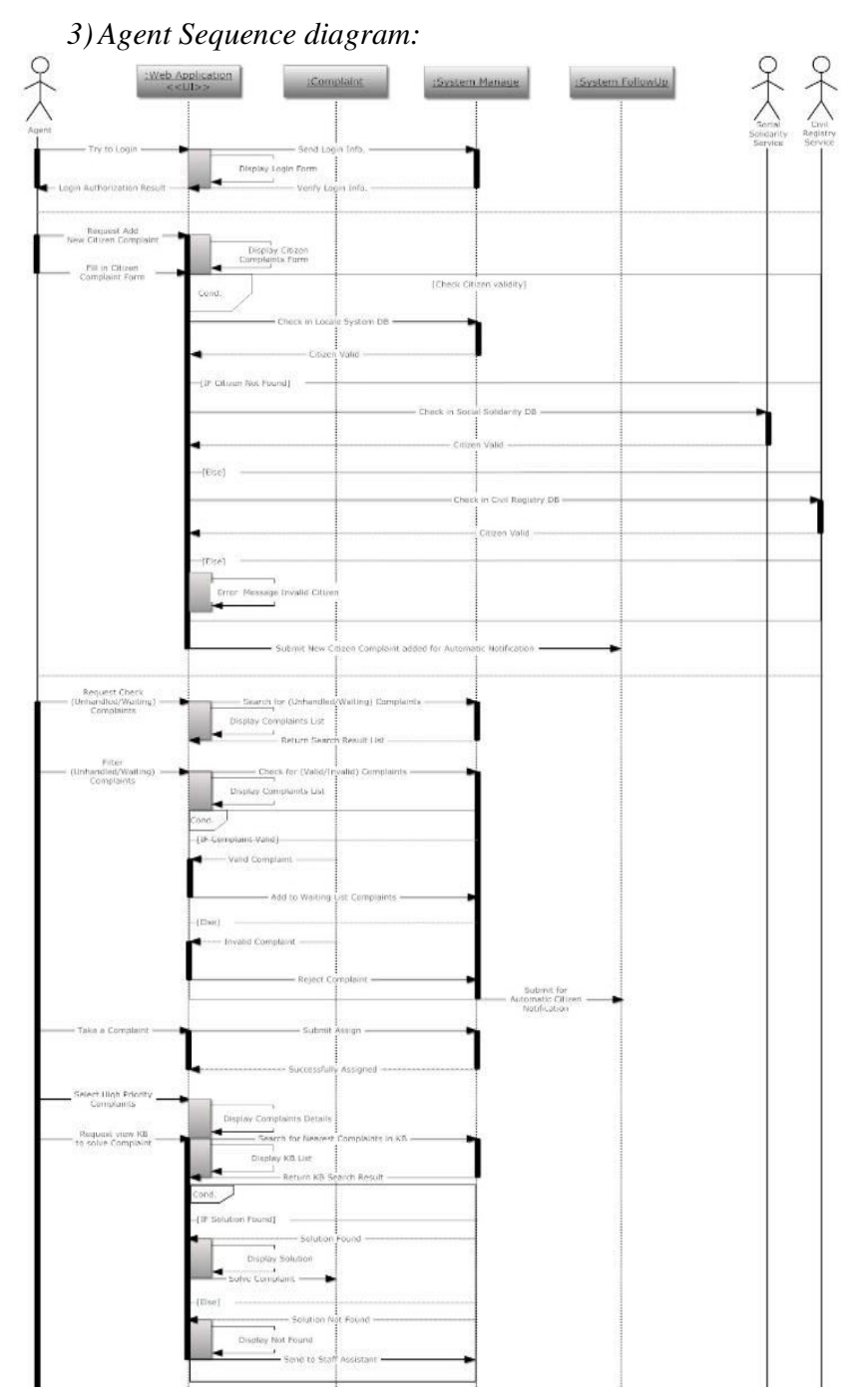

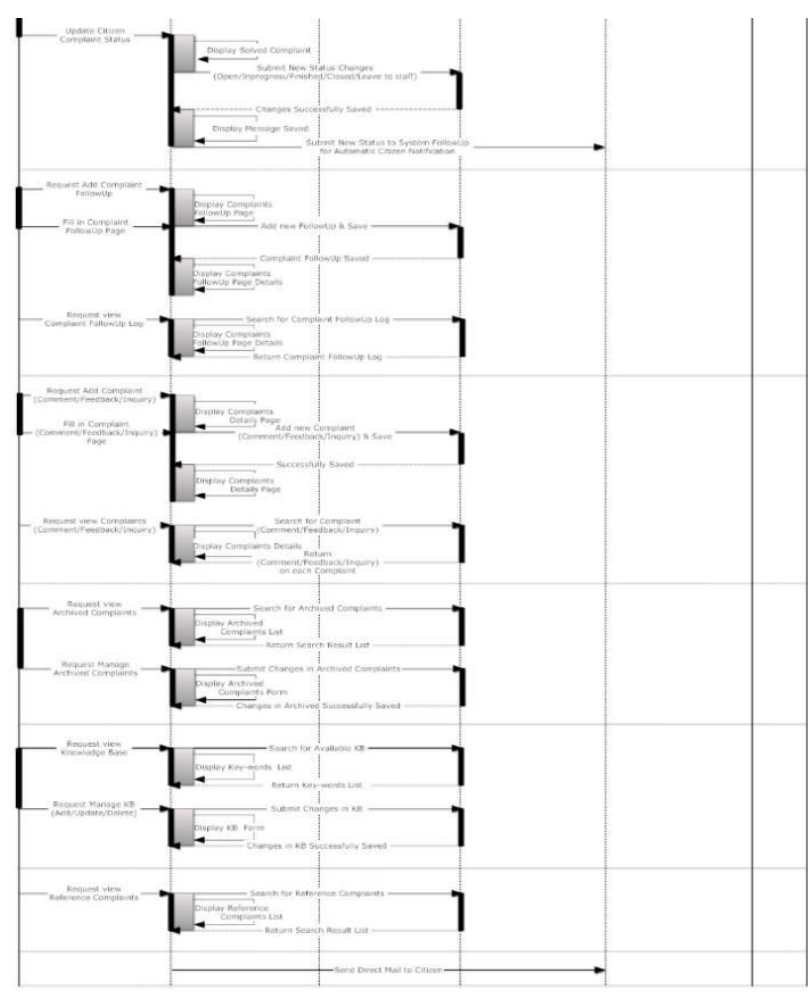

Figure 8: Agent Sequence Diagram for the Proposed System.

4) Staff Sequence diagram:

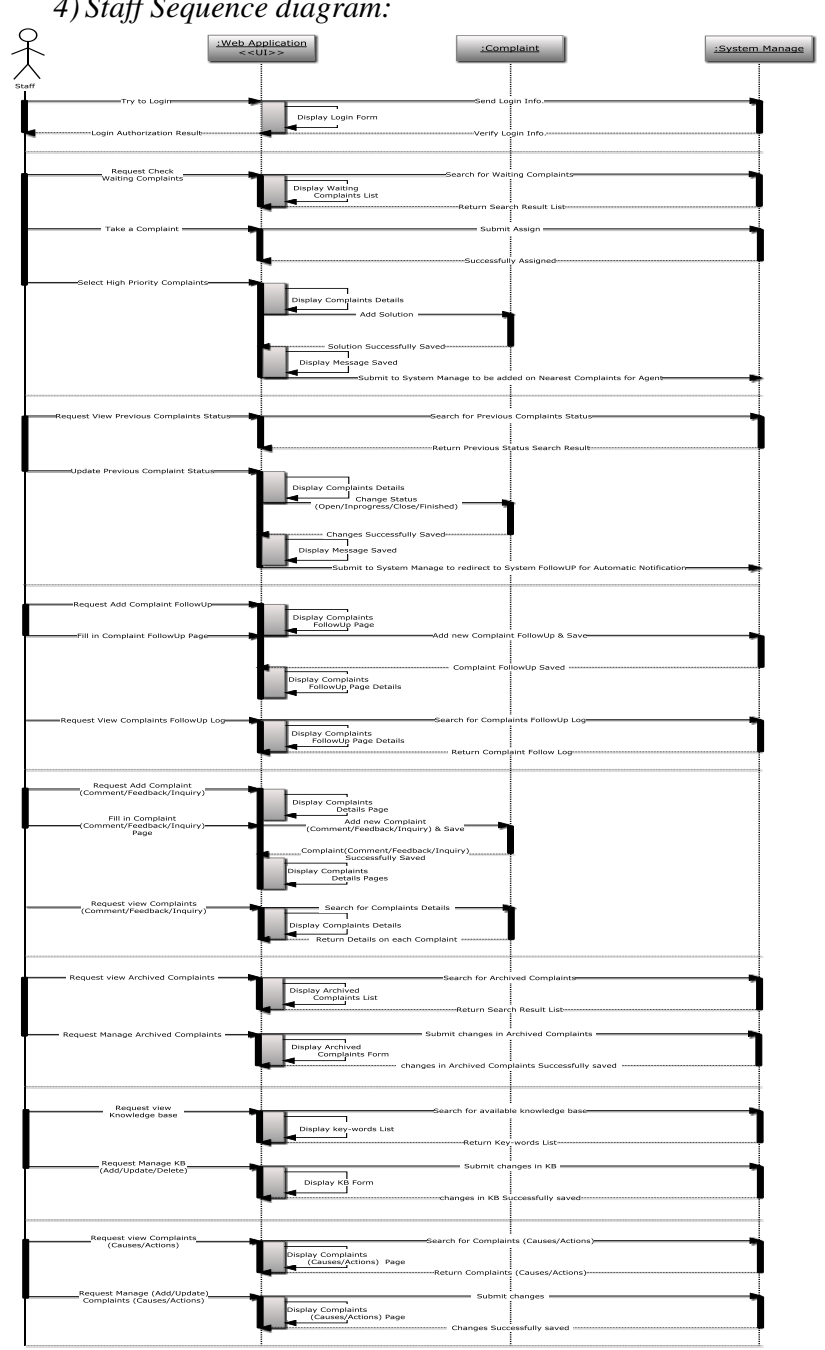

Figure 9: Staff Sequence Diagram for the Proposed System. 
5) Supervisor Sequence diagram:

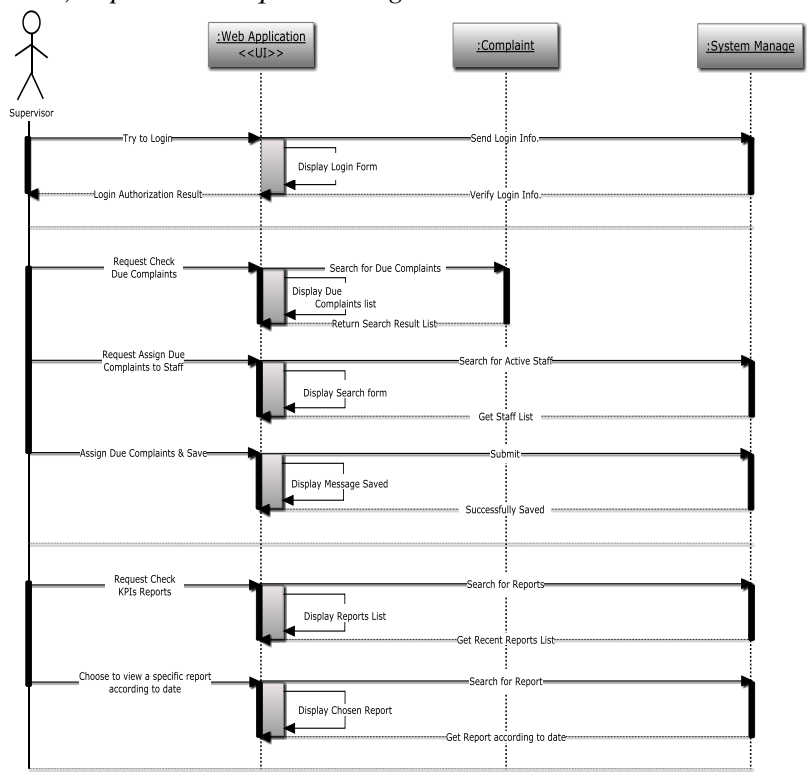

Figure 10: Supervisor Sequence Diagram for the Proposed System.

\section{Class diagram}

This diagram describes the systems' structure through showing systems' classes, attributes of classes and relations between class. In this system we have three main classes 'Citizen' class, 'Complaint' class, and 'User' class. Each one of these three main classes have general relationship with other classes, as shown in fig. 11.

- There is a 1 to $\mathrm{n}$ relation between 'Marital Status' class and 'Regions' class with 'Citizen' class. Which means that each Citizen must define his marital status such as (single, married, widowed, divorced) and the location he belongs to on the web. There is a dependent relationship between 'Governorates' class and 'Regions' class as each governorate contain many regions.

- Also, there is a 1 to $\mathrm{n}$ relation between 'Complaint' class and each of 'Complaint Status' class, 'Complaint Causes' class, 'followUp' class and itself. As each complaint has status such as (open, in progress, pending, solved, closed...etc); also, each problem raised through some causes led to that complaint; each complaint could be followed up in a way of interaction between Citizens and Users through the complaint and the complaint may have a reference as a previous related complaint from the same Citizen for that it has a self-relationship. 'Sub classification' class depends on 'Classification' class and has a relation 1 to $\mathrm{n}$ with the 'Complaint' class.

- Each user on the system must have a role for that there is a relation 1 to $\mathrm{n}$ between 'Role' class and 'User' class.

- Each complaint takes a status added by user for that there is a relation 1 to $\mathrm{n}$ between 'User' class and 'Complaint Status' class.

- Each Citizen who refers to the web service can take a survey in a way to but feedback and state a problem acquire. All feedback will be recorded in 'Site Survey' class. This class is dependent on each Citizen enter the web.
- 'Questions' class and 'Answers' class are dependent classes used by admin. Admin define the questions for each question there are many answers has a certain score.

- 'Civil Registry Service' class and 'Social Solidarity Services' class are provided to offer different services in the system if the user has the authority to get these services. These classes will rout user to related page that they requested for.

- 'Knowledge Base' class is independent class where users can add keywords to help them in solving complaints and search for nearest solution.

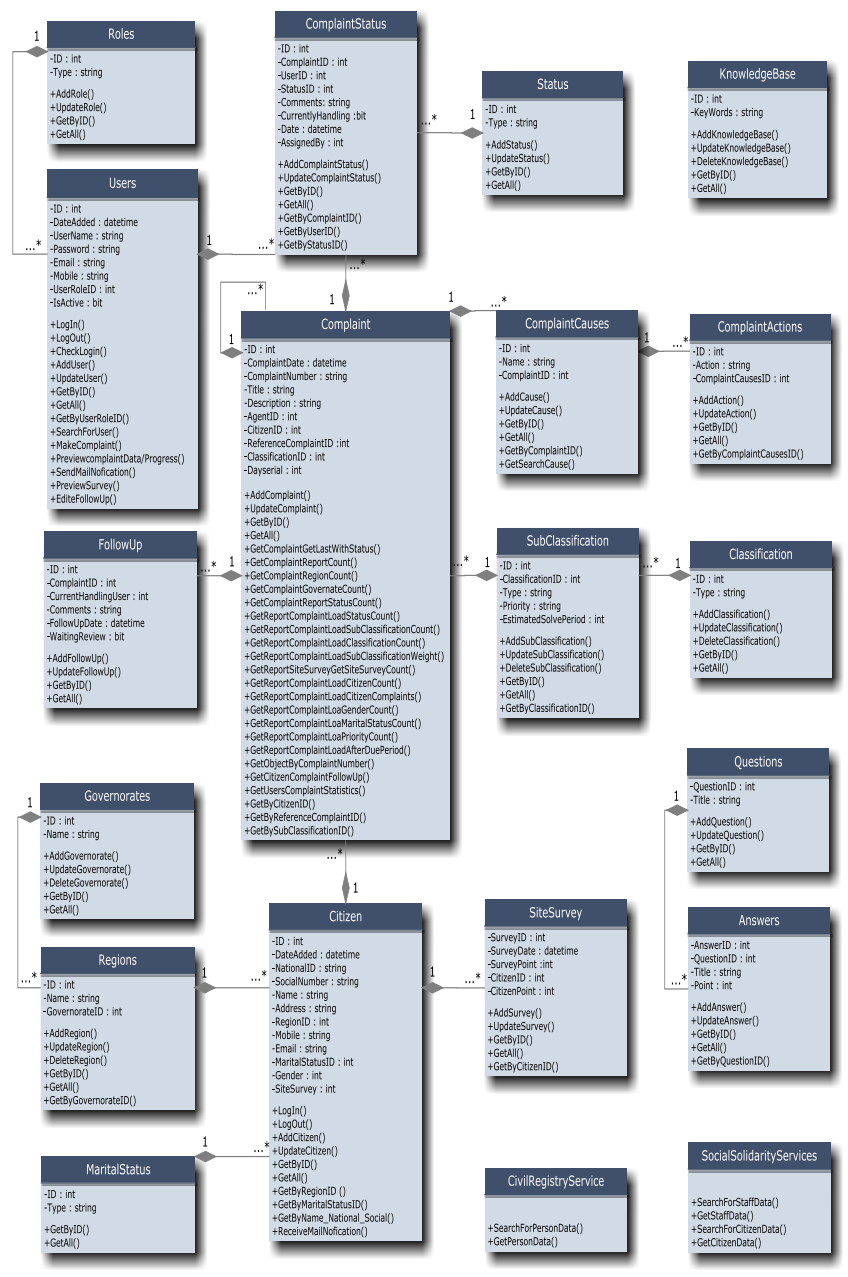

Figure 11: Class Diagram for the proposed e-Complaint System.

\section{SYSTEM IMPLEMENTATION}

After explaining the proposed system analysis and the proposed system design, the next step is the proposed implementation of the system.

In this section, the researchers will firstly discuss the service implementation with the web-application interface development. Then exploring the most important reports extracted for the evaluation result.

\section{A. Implementation Development}

\section{1) Services}

The word 'Service' has many definitions based on the context in which it is used and based on the industry in which the service is provided or performed. 
DEFINITION 1. A service is "a component of an automated sub-process representing a unit of work". It performed as part of a business function, such as verifying customer contact information or validating recent customer purchasing activity ...etc. (e.g., "Get Customer Record").

The new catch-all word "Services" is making its rounds in the industry of late. But, just like the term "Component" it's a word that is easily overloaded with different kinds of meanings. The term Service is used in a few other industry buzzwords, namely Web Services, Service Oriented Architecture (SOA), Enterprise Service Bus (ESB) and Application Service Provider (ASP). It's an extremely overloaded term [62]. However, the researcher defines Service as software entity that is designed in isolation however provides near frictionless interoperability. It's a strange almost mythical combination of competing requirements, which it is both isolated and interoperable. Services are not Objects nor are they the same as Components; however, that doesn't mean that Services using Objects or Components cannot be implemented. This fact causes a lot of confusion, just because you can implement something with $\mathrm{X}$ does not imply that same thing is an $\mathrm{X}$. That $\mathrm{X}$ is just the implementation strategy; the actual thing that's implemented which is called Services has certain welldefined characteristics.

In this study the researchers use the 'Service' to connect different databases from different platforms to retrieve certain data. In the following section the researcher will explore the three main Services that used in the proposed ecomplaint web service to get the Citizen and Staff data and how it's work.

\subsection{CivilRegistryService}

This is the first service used to retrieve 'Citizens' details from the 'Civil Registry' if they don't belong to the 'Social Solidarity' Citizens. The service works as following:

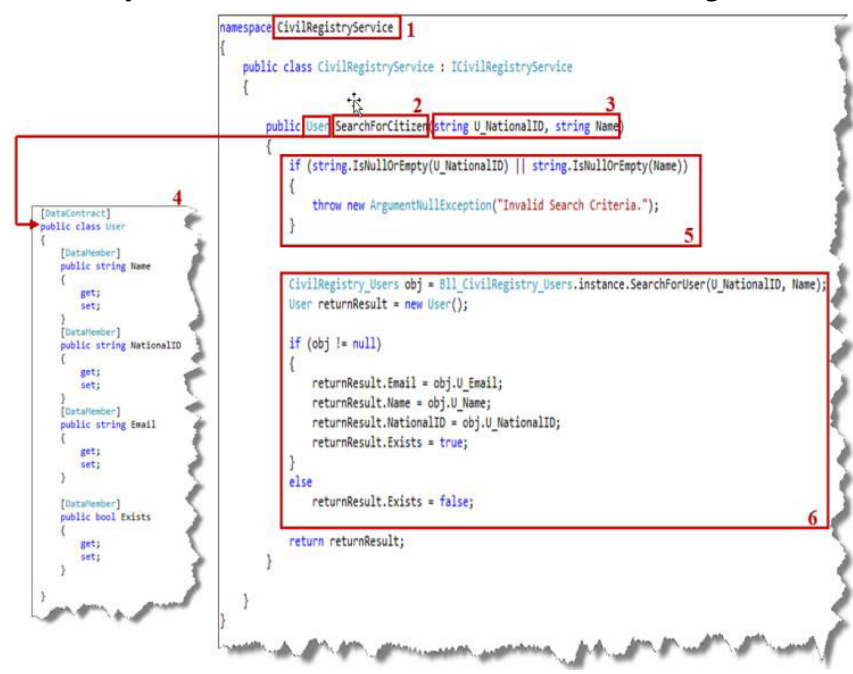

Figure 12: Civil Registry Service (Code Snippet).

\section{Service description:}

1. Service name: CivilRegistryService,

2. Function: SearchForCitizen,

3. Parameters: U_NationalID and Name from type string,

4. Signature or Return Type: User,

5. Function operation: check the two supplied inputs,

6. Service main operation: start search with given data, check if it's found fill return object and set property found, else not found without data.

\subsection{SocialSolidarityService}

This is the second service used to retrieve 'Citizens' details from the 'Social Solidarity'. The service works as following:

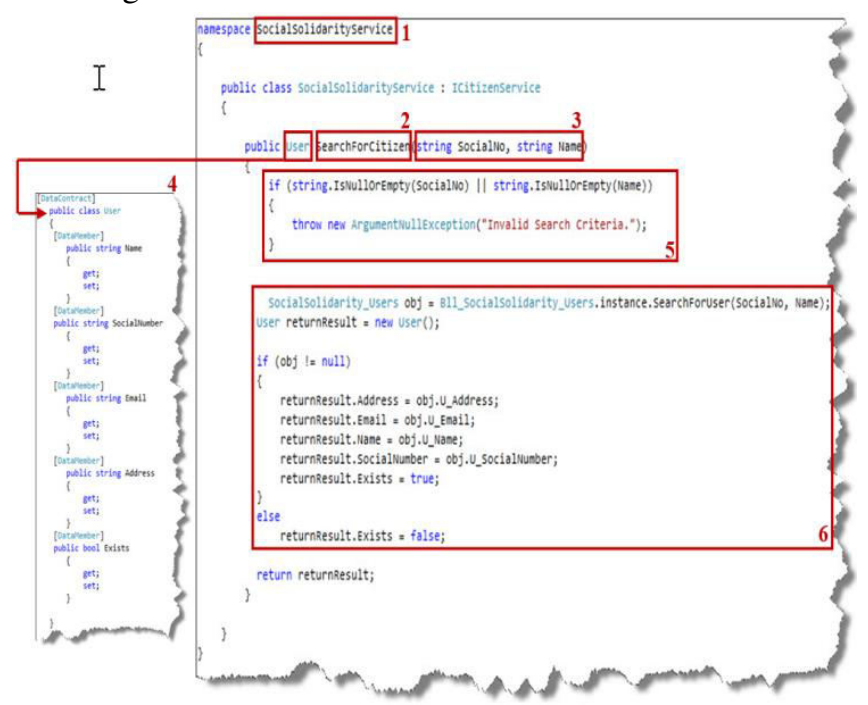

Figure 13: Social Solidarity Service (Code Snippet).

\section{Service description:}

1.Service name: SocialSolidarityService,

2. Function: SearchForCitizen,

3. Parameters: SocialNo. and Name from type string,

4. Signature or Return Type: User,

5. Function operation: check the two supplied inputs,

6. Service main operation: start search with given data, check if it's found fill return object and set property found, else not found without data.

\subsection{StaffService}

This is the third service used to retrieve 'Staff' details from the 'Staff DB'. The service works as following:

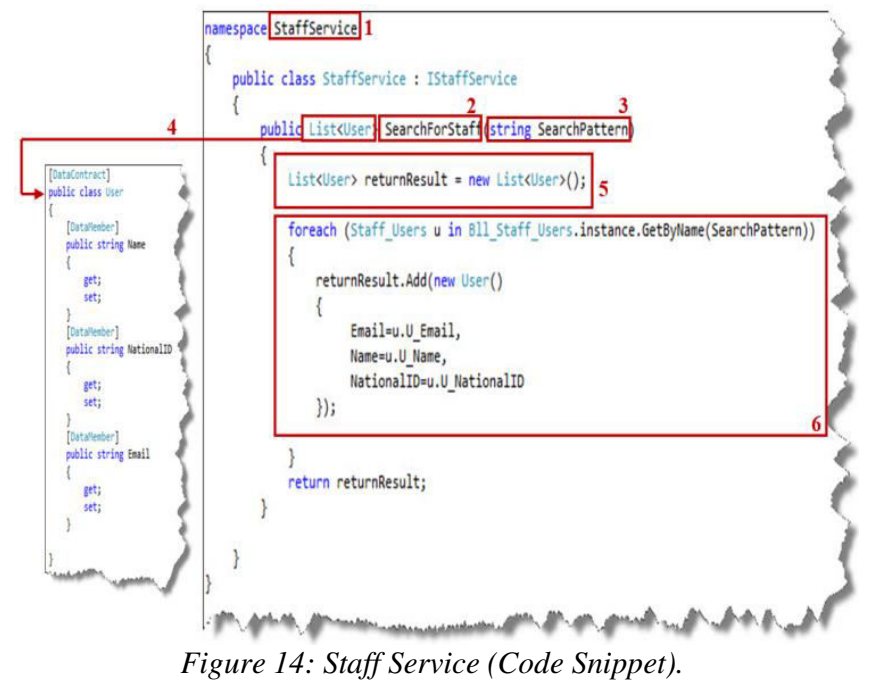

Service description:

1.Service name: StaffService,

2. Function: SearchForStaff,

3. Parameters: Pattern (custom search) from type string,

4. Signature or Return Type: List of User,

5. Function operation: New list of objects of return type,

6. Service main operation: select data iterate in search result and make new object in each round then add it to the return list. 
For implementing the model, the researchers tried to develop a web application to exhibit the ability of the model as well as efficiency in e-Gov since it could be developed thoroughly. The researchers implement the three services in the web application each according to the operation that call the service to retrieve the certain data, as shown in the following subsections.

\section{2)Modules}

E-CCMS is used to manage customer complaints, corrective and preventive actions and other case types with a focus on the development of strategies for improvement. The following is an overview of some of the functionality within e-CCMS.

In this study the researchers supposed that to complete the e-complaint system cycle there is a need for five modules to implement this cycle; first module related to the 'Citizen' who want to fill his complaint; second module the 'Admin' who manage the system users; third module the 'Agent' who will deal with the Citizen complaints; fourth module the 'Staff' who analyze the causes and actions of each complaint; and fifth module the 'Supervisor' who view the overview reports and take decisions for improvements.

\subsection{Citizen Module}

In this module, there are two services required to get the Citizen data first one is the 'Civil Registry Service'; this service called when the Citizen who need to login not in the 'Social Solidarity DB' and login with his 'NationalID' and 'Name', second one is 'Social Solidarity Service'; this service called when the Citizen who need to login belongs to the 'Social Solidarity DB' and has a social number in this case he login with his 'SocialNo.' and 'Name', as shown in fig. 15 .

\section{eComplaint System}

"We're commencted to improve our socuices to you"

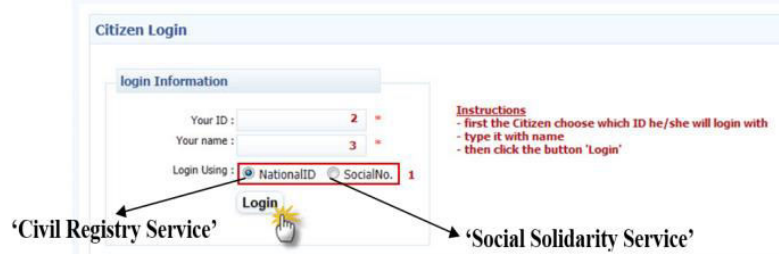

Figure 15: Citizen Login Screen (Authentication).

After the Citizen successfully, login the system manages ask citizen if he/she wants to take a survey, as shown in fig. 16.

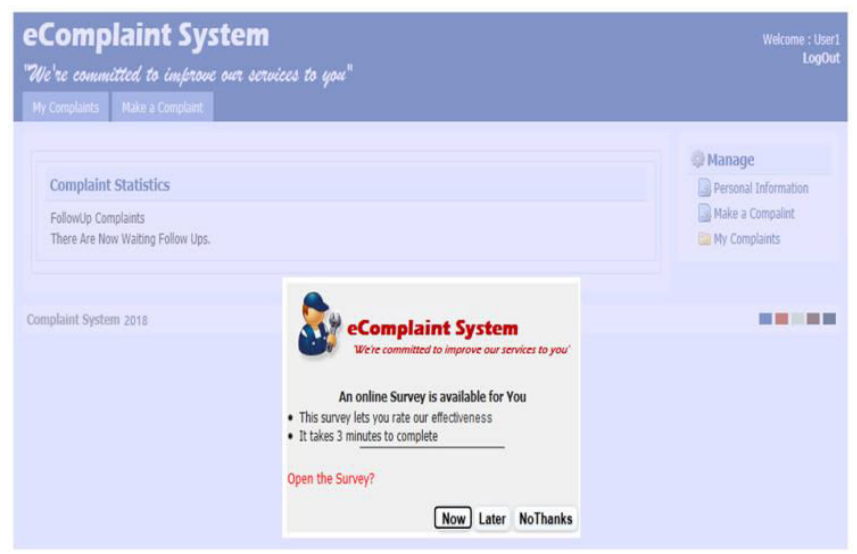

Figure 16: Take a survey (Citizen Module).
The following snap show sample of the Survey Page appears to Citizen when he clicks 'Now' button, as shown in fig. 17.

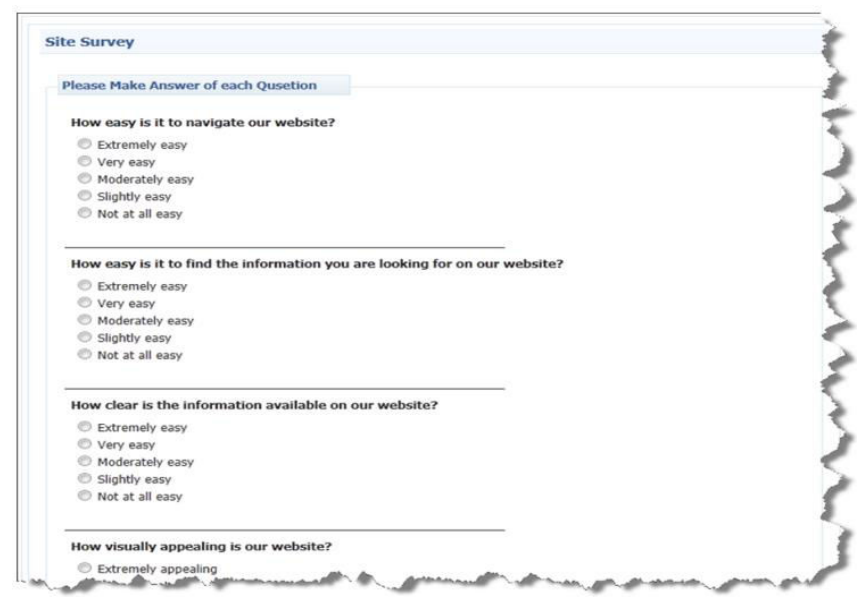

Figure 17: Survey Page (Citizen Module).

Fig.18. shows the Citizen main screen; if he/she has a waiting follow up it will appear in the complaint statistics that's if Citizen complained before.
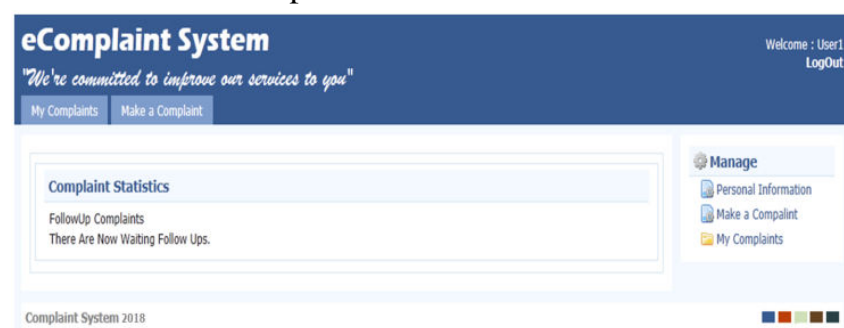

Figure 18: Citizen Main Page.

Fig.19. shows If Citizen want to check status of his old complaint, view comments .... etc.

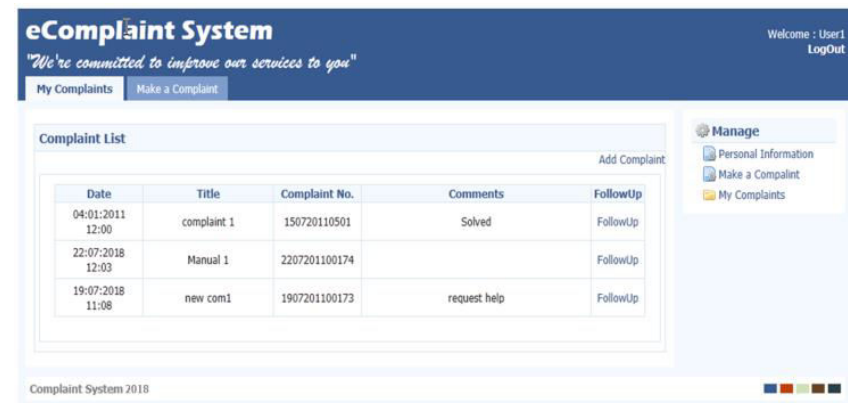

Figure 19: Previous Citizen Complaints.

Fig.20. shows the follow up page if Citizen want to comment in Changes.

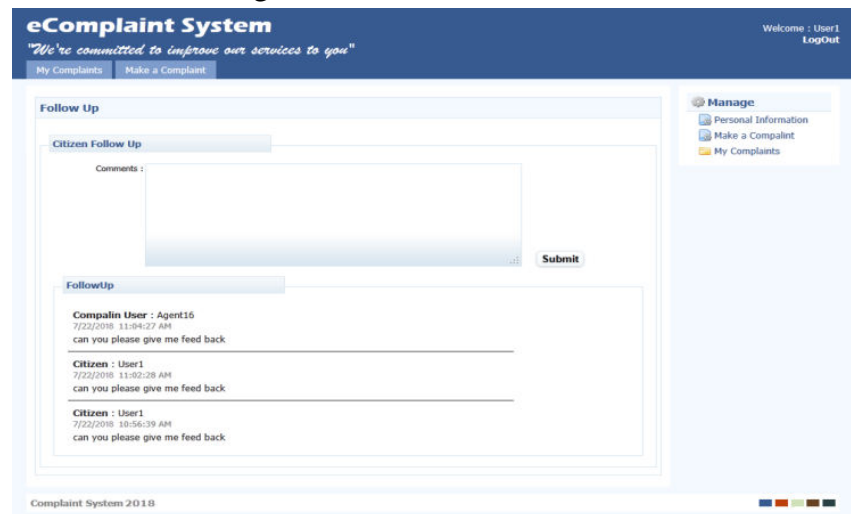

Figure 20: Follow Up Page (Citizen Module). 
Fig.21. shows if Citizen wants to make a new complaint.

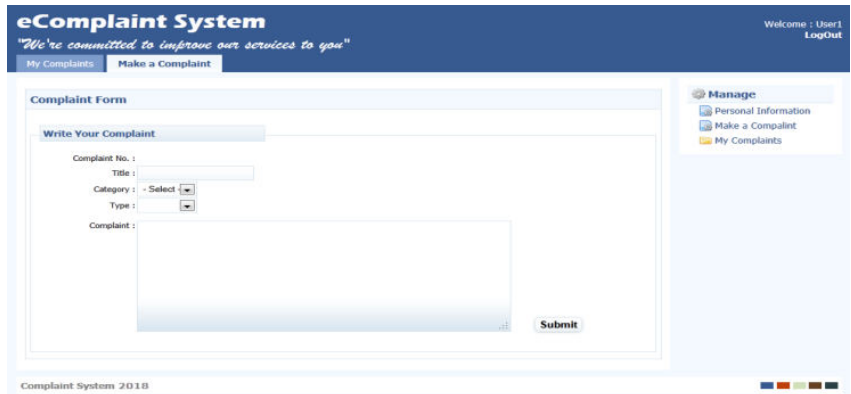

Figure 21: Make a Complaint Page (Citizen Module)

Fig.22. shows the edit info. Page for Citizens, this page also appears by default as a first screen for Citizen who enters the web for the first time to complete his data to be saved in 'Local System DB'.

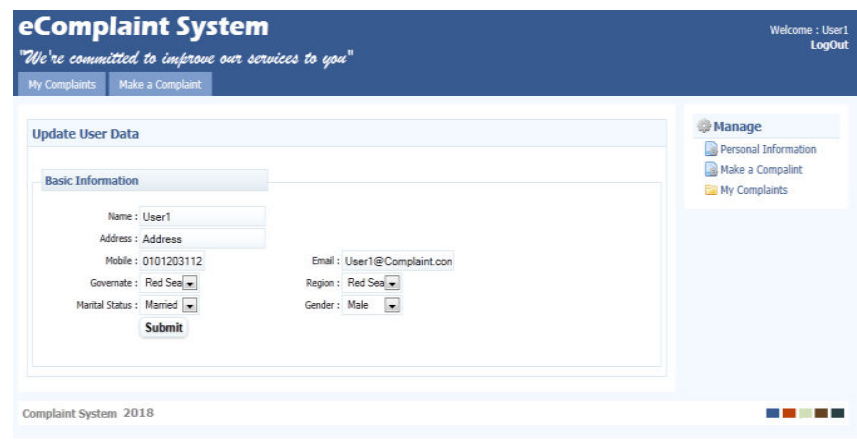

Figure 22: Edit Info. Page (Citizen Module).

\subsection{Admin Module}

In this module, there is one service required to get the Staff data from 'Staff DB' this service will be called when admin tries to add new users to the system, as shown in fig. 24 .

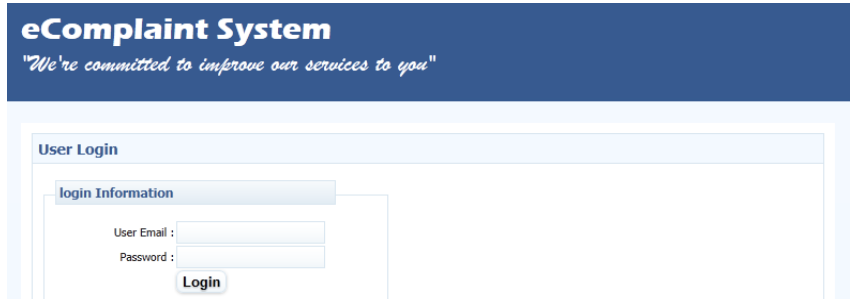

Figure 23: Admin Login Screen.

Fig.23. shows the Login Screen to get started with the webapplication. Only Authenticated users can login. This account is created by the Administrator only. This also is provided to all the main system users such as (Admin, Agent, Staff and Supervisor) to keep track of all the system activities each according to his role on the system.

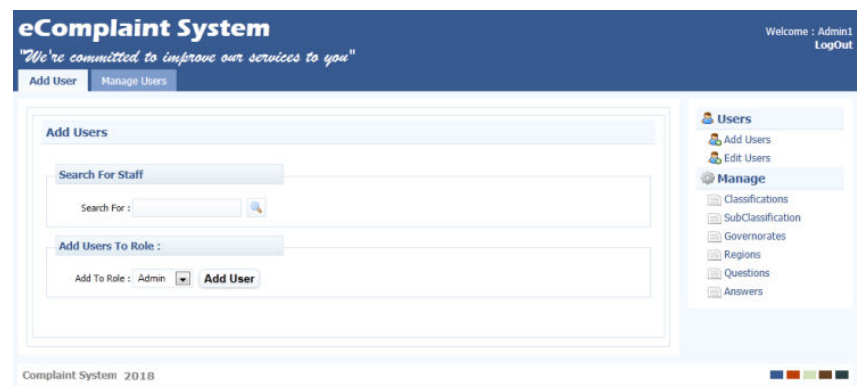

Figure 24: Add New User Screen (Admin Module).
Fig.24. shows the main screen in the admin module consists of two tab the first one is "Add User" in this page when the admin wants to import a new user to the system he searches for users from the 'Staff DB' through calling the 'Staff service' to be added in the 'local system DB' then assign roles to them.

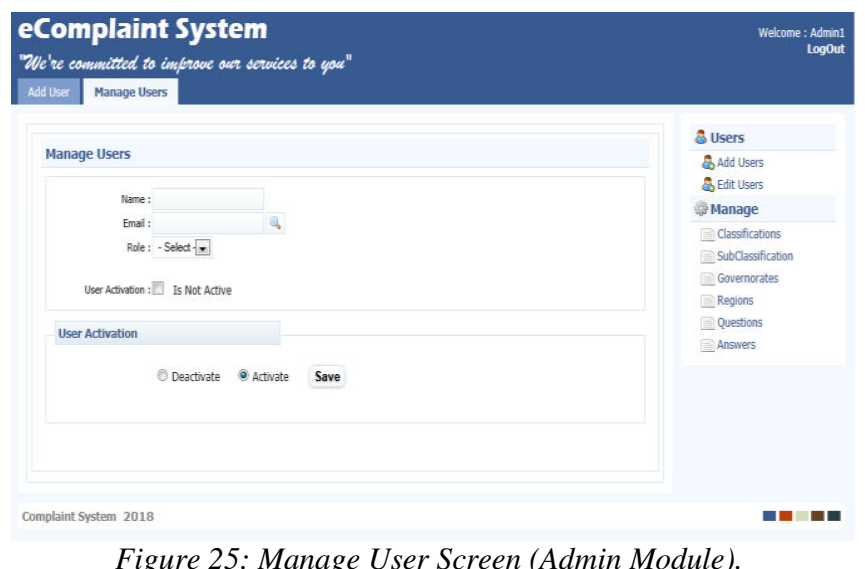

Fig.25. shows the second tab "Manage User" in this page admin can search for users from the 'Local system DB' and change their role or deactivates or activates them.

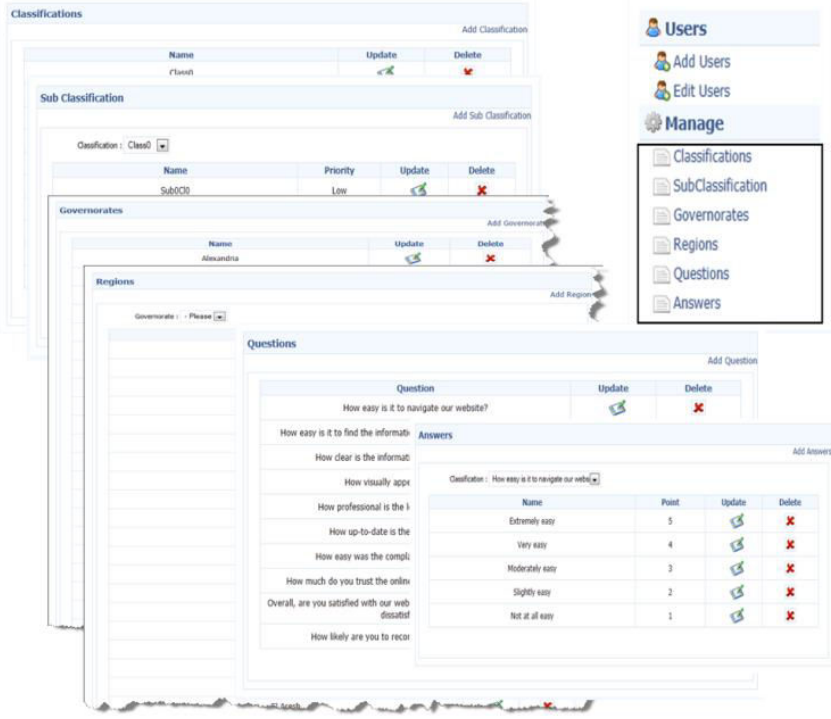

Figure 26: Lookups (Admin Module).

\subsection{Agent Module}

In this module, there are two services required to get the Citizen data; the agent will try to login as authorized user on the system same as admin after that the main page that contains the basic tasks will be appeared, as shown in fig. 27 .

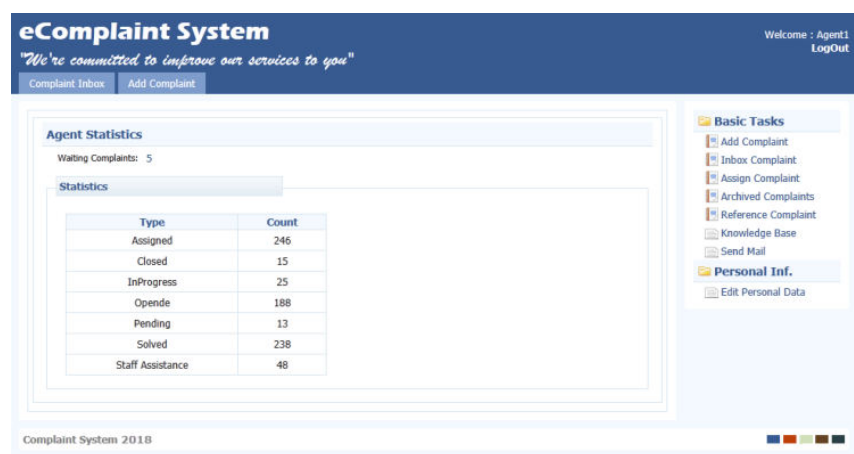

Figure 27: Agent Main Page. 
When the agent tries to add new complaint delivered to him even by call or face-to-face or by complaint letter, he starts searching for the Citizen first then adds his complaint, as shown in fig. 28 .

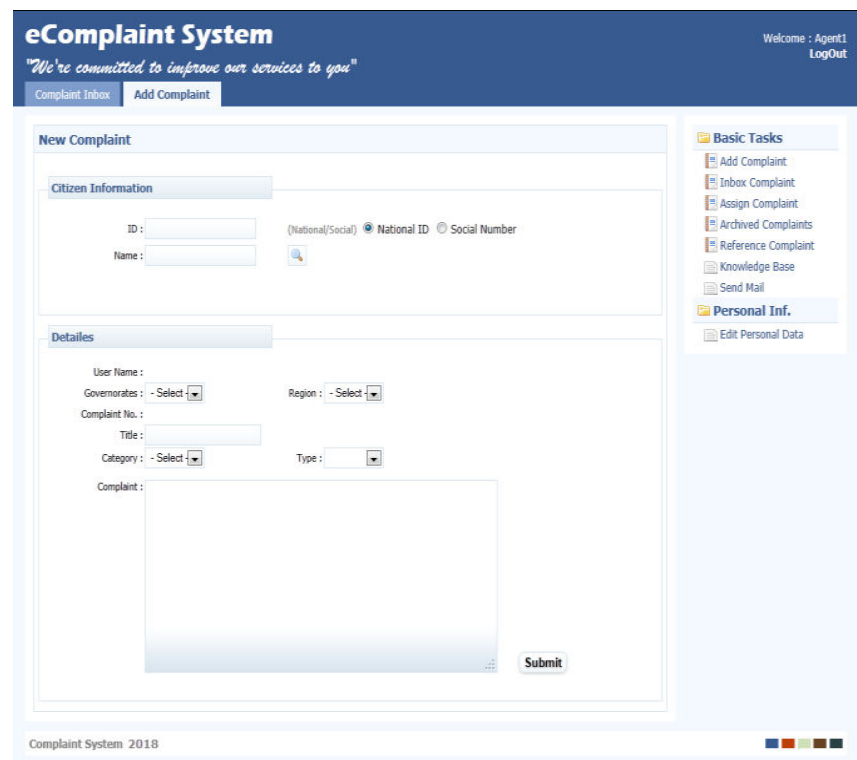

Figure 28: Add New Complaint Page (Agent Module).

Here agent can search for waiting complaints list, as shown in fig.29. Then filter and assign them, as shown in fig.30. After that view details of the complaint to solve, as in fig. 31 .
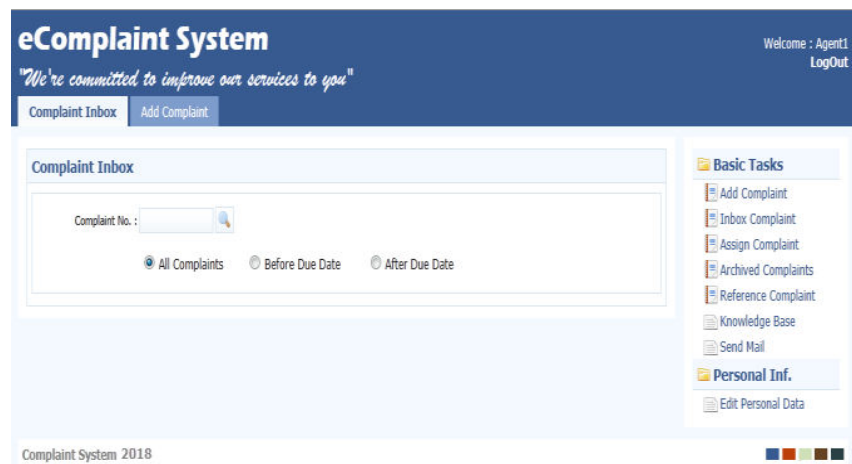

Figure 29: Complaint Inbox (Agent Module).

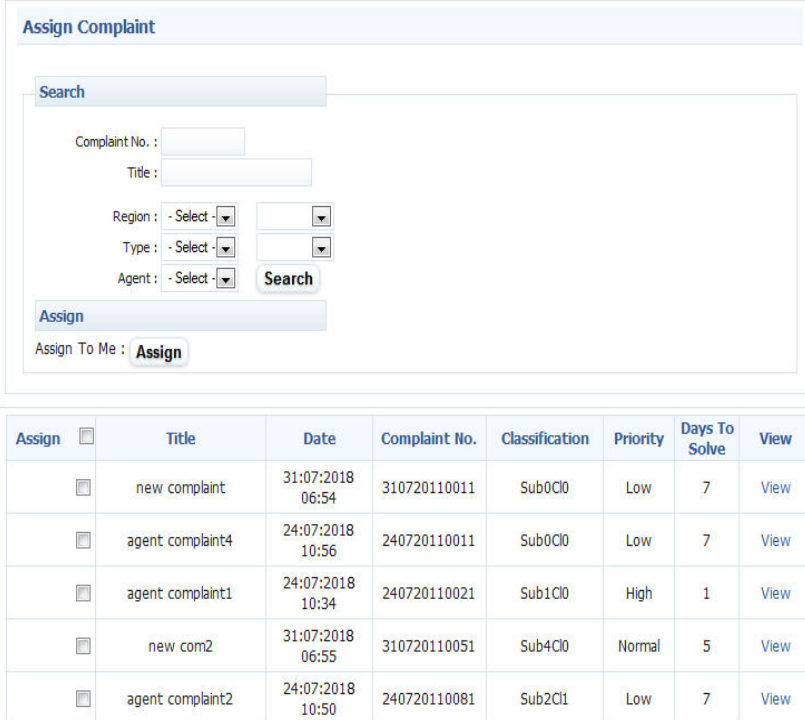

Figure 30: Assign Complaint Page (Agent Module).

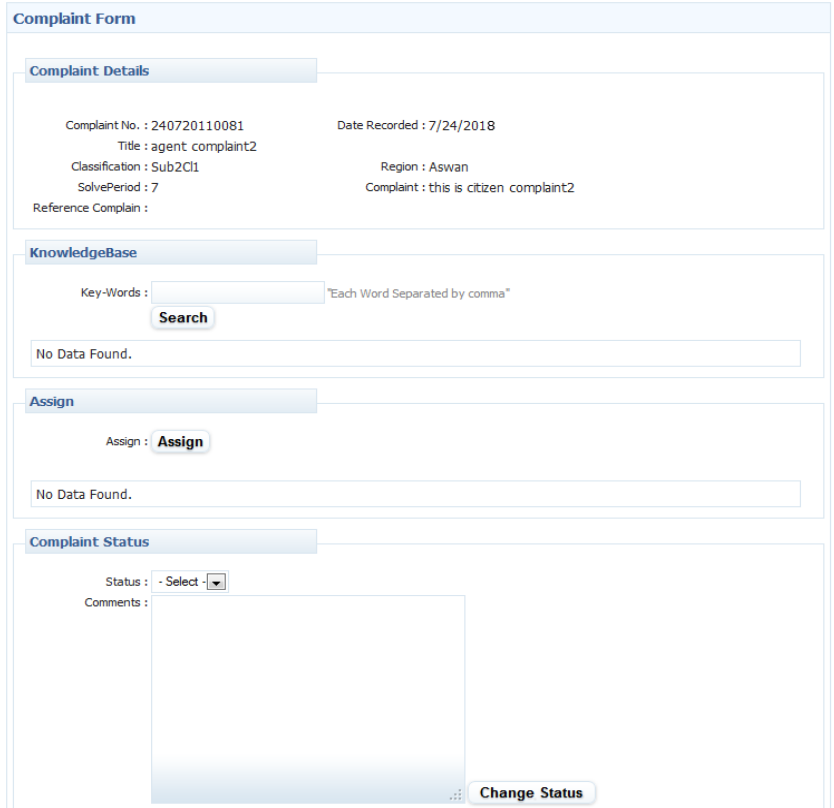

Figure 31: Complaint Details (Agent Module).

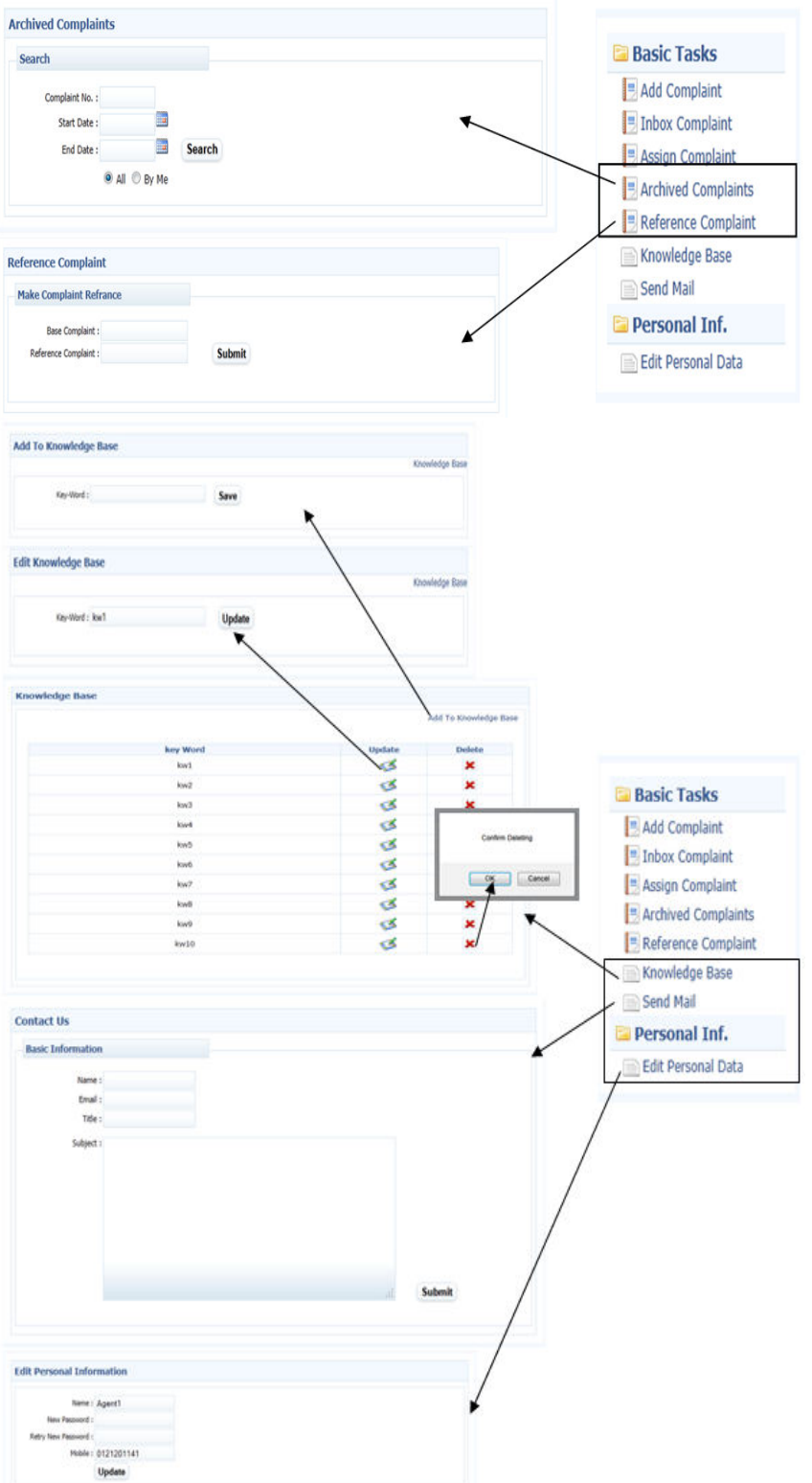

Figure 32: Basic Tasks (Agent Module). 


\subsection{Staff Module}

In this module, there is no service will be called only staffs tries to add new solutions, define causes and actions; in other word, make a complete analysis for complaints.

Fig.33. shows the staff main page that appears after login as authorized user on the system.

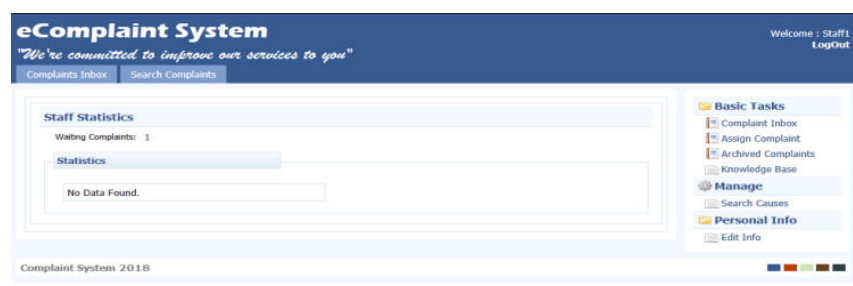

Figure 33: Staff Main Page.

Fig.34. shows when staff tries to search for the complaint causes and actions.

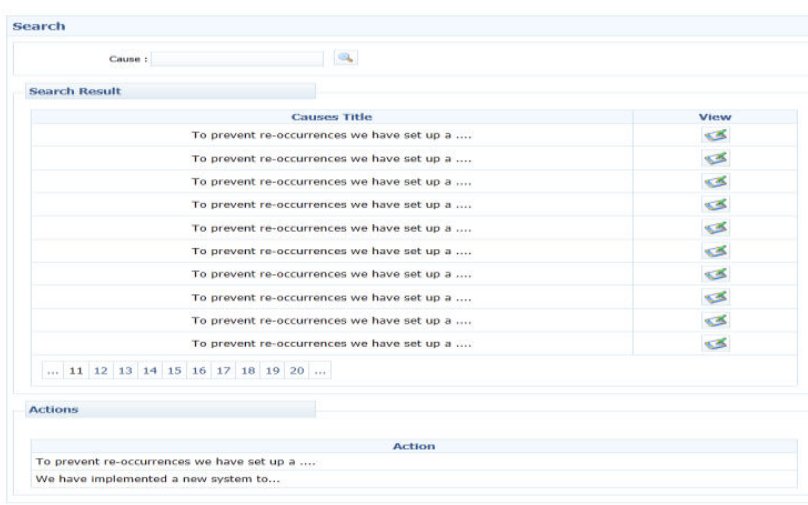

Figure 34: Cause Search Page (Staff Module).

Fig.35. shows when staff tries to view certain complaint details or try to edit complaint cause or assign it.

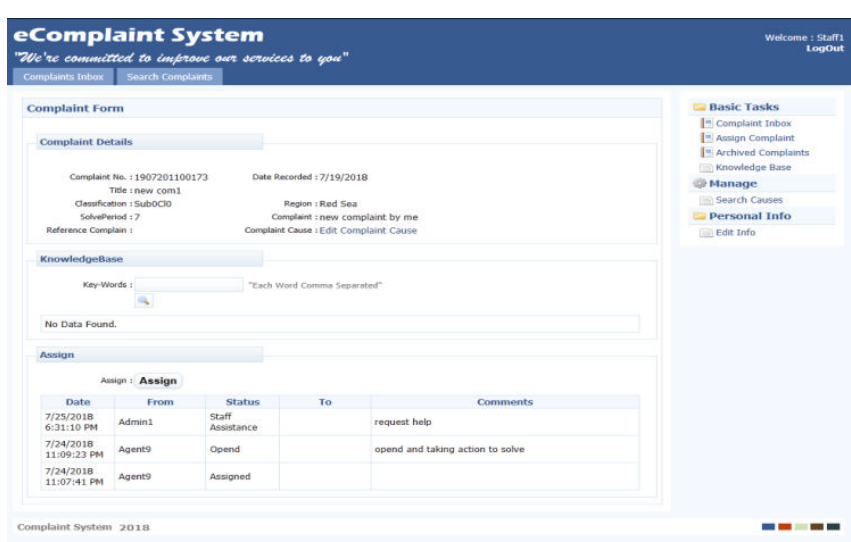

Figure 35: Complaint Details (Staff Module).

Fig.36. shows when staff tries to add new cause or action.

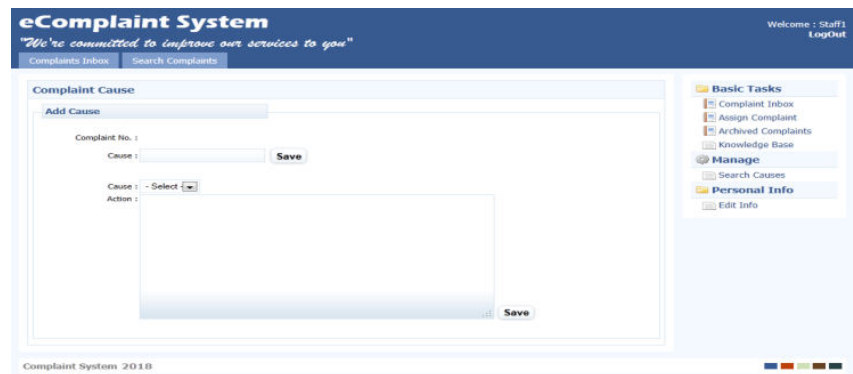

Figure 36: Edit Causes and Actions Page (Staff Module).

\subsection{Supervisor Module}

In this module, there is no service will be called only supervisor tries to view due complaints, as shown in fig.38 then assign them to active staffs according to user statistical report, as shown in fig.39; also view all critical reports that will help in decision making and improvement cycle.

Fig.37. shows the supervisor main page that appears after login as authorized user on the system. Hear supervisor can view if there is any waiting complaint or overdue complaint that needs to be handled; also, supervisor can assign complaints and view the statistical reports.

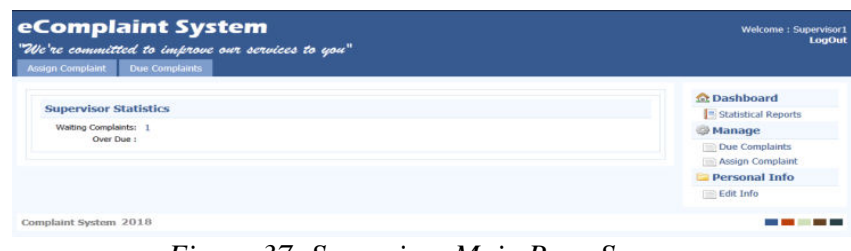

Figure 37: Supervisor Main Page Screen.

Fig.38. shows the due complaints that need to be handled. Hear supervisor can search by certain date and assign complaints to certain staff; also view its details.

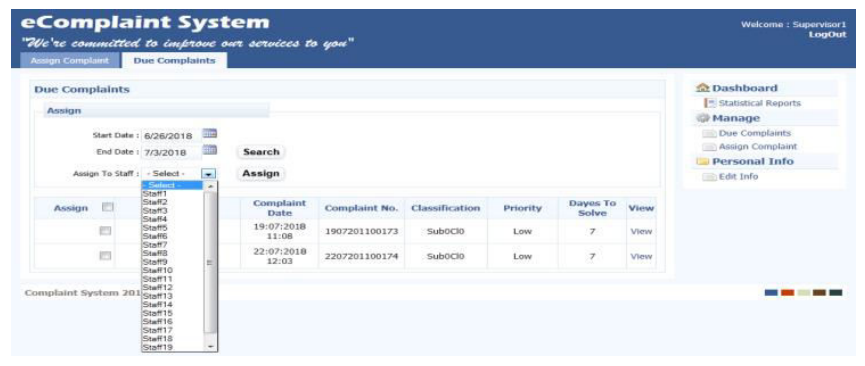

Figure 38: Due Complaints (Supervisor Module).

Fig.39. shows the assign complaint tab on the supervisor module.

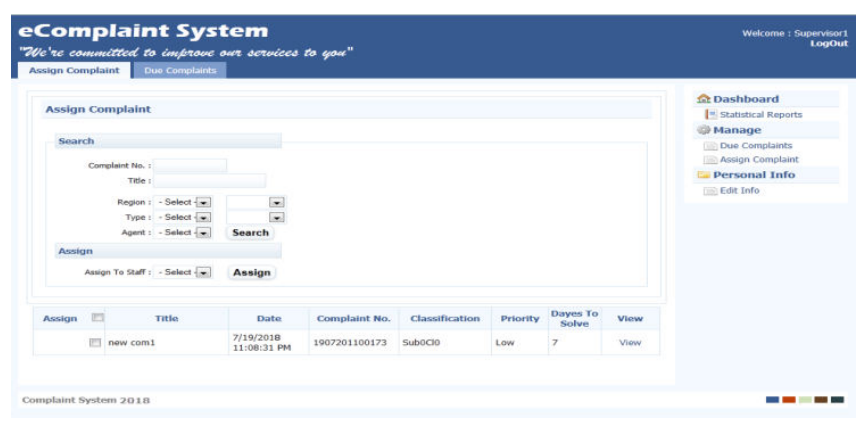

Figure 39: Assign Complaint (Supervisor Module).

Fig.40. shows when supervisor tries to view certain complaint details or assign it to staff.

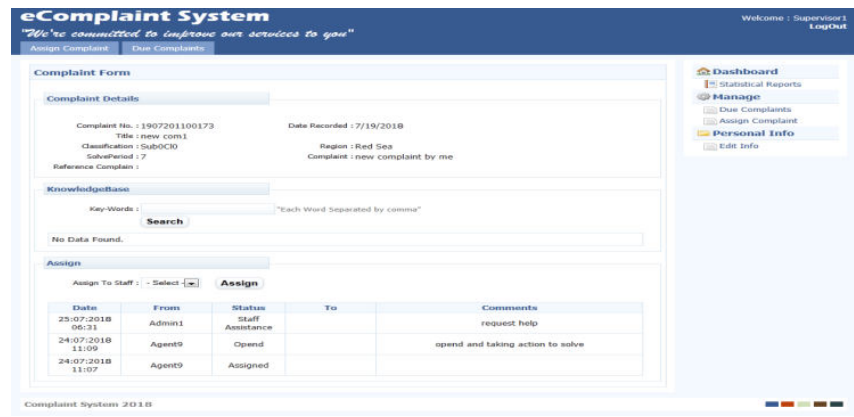

Figure 40: Complaint Details (Supervisor Module). 


\section{B. Evaluation Results}

Due to time and resource constraints, the researcher was unable to incorporate the proposed model into a physical governmental system or any organization. However, using several test scenarios applied to the model shows that it is applicable to be applied on real data if it is available and will have the same performance.

For evaluation purposes, the researcher has created a random generator, which is able to generate random complaints scenarios that serve as input to the proposed model for creating Citizen Complaints. The experimental results clearly indicate that using SOA is suitable to aid in creating e-complaint systems.

\section{1) KPIs Report Analysis}

In this section the researcher will explore the most important Key Performance Indicators (KPIs) in the proposed e-complaint web service.

Key Performance Indicator is an industry jargon term for a type of Measure of Performance. KPIs are commonly used by an organization to evaluate its success or the success of an activity in which it is engaged. Sometimes success is defined in terms of making progress toward strategic goals, but often, success is simply the repeated achievement of some level of operational goal (zero defects, 10/10 customer satisfaction etc.). Accordingly, choosing the right KPIs is reliant upon having a good understanding of what is important to the organization. 'What is important' often depends on the department measuring the performance - the KPIs useful to a Finance Team will be quite different to the KPIs assigned to the sales force, for example. Because of the need to develop a good understanding of what is important, performance indicator selection is often closely associated with the use of various techniques to assess the present state of the business, and its key activities. These assessments often lead to the identification of potential improvements; and consequently, performance indicators are routinely associated with 'performance improvement' initiatives. A very common method for choosing KPIs is to apply a management framework such as the balanced scorecard.

The researcher has implemented the system using random generator by entering samples of data for 3 years $(2016,2017$ $\&$ 2018). Also, the researcher has tested the system with $(12,015)$ complaint case; 11,162 cases are solved and 848 cases still unsolved. The number of Governorates covered by system are (29) area.

Refer to research result, the researcher counts the cases on the system by gender as: 5640 cases by male and 6375 cases by female. And count Married/Single cases as 4674 married citizen and 7341 single citizens. The system also has received (6999) feedback.
TABLE 3: SAMPLES RANDOMLY GENERATED.

\begin{tabular}{|ll|c|}
\hline \multicolumn{2}{|c|}{ System Performance Survey } \\
\hline 1) & $\begin{array}{l}\text { System Failures } \\
\text { Failures to print a complete report. }\end{array}$ & 1095 \\
\hline 2) & $\begin{array}{l}\text { Survey Total Days } \\
\text { Total days conducted. }\end{array}$ & 12,015 \\
\hline 3) & $\begin{array}{l}\text { Number of Complaints } \\
\text { Total cases under study. }\end{array}$ & 848 \\
\hline 4) & $\begin{array}{l}\text { Number of Unsolved Cases } \\
\text { Total number of unsolved cases depends on survey conducted period. } \\
\text { (Assigned/Opened/In-Progress/Pending/Closed/Needs Staff Assistance) }\end{array}$ & \\
\hline 5) & $\begin{array}{l}\text { Number of Solved Cases } \\
\text { Total number of solved cases depends on survey conducted period. }\end{array}$ & 11,162 \\
\hline 6) & $\begin{array}{l}\text { Coverage Areas } \\
\text { Number of Governorates covered by the system. }\end{array}$ & 29 \\
\hline 7) & $\begin{array}{l}\text { Male/Female Cases } \\
\text { Total number of Male/Female Cases. }\end{array}$ & $5640 / 6375$ \\
\hline 8) & $\begin{array}{l}\text { Classification Categories } \\
\text { Types of Complaints according to case study. (number) }\end{array}$ & 10 \\
\hline 9) & $\begin{array}{l}\text { Citizen Analysis } \\
\text { Total number of Married/Single (single-divorced-widowed) cases. }\end{array}$ & $4674 / 7341$ \\
\hline 10) & $\begin{array}{l}\text { Complaint Status Count } \\
\text { Total number of solved cases by most active user. (Agent) }\end{array}$ & Nos \\
\hline 11) & $\begin{array}{l}\text { Feedback } \\
\text { Total number of Completed/Ongoing feedbacks by Citizens. }\end{array}$ \\
\hline 12) & $\begin{array}{l}\text { Association Performance Improvements } \\
\text { Dose the system improves the performance of the association? }\end{array}$ \\
\hline 13) & $\begin{array}{l}\text { Attitude towards using } \\
\text { Feeling unfavourable towards using the system. }\end{array}$ \\
\hline 14) & $\begin{array}{l}\text { Meets its purpose } \\
\text { Dose the system meet its purpose? }\end{array}$ & yes \\
\hline & $\quad$ Nog/3001 \\
\hline
\end{tabular}

The following section is related to the 'Supervisor Module' here the researcher will explore the most important KPIs extracted from the e-complaint system based on SOA as evaluation result for this study.

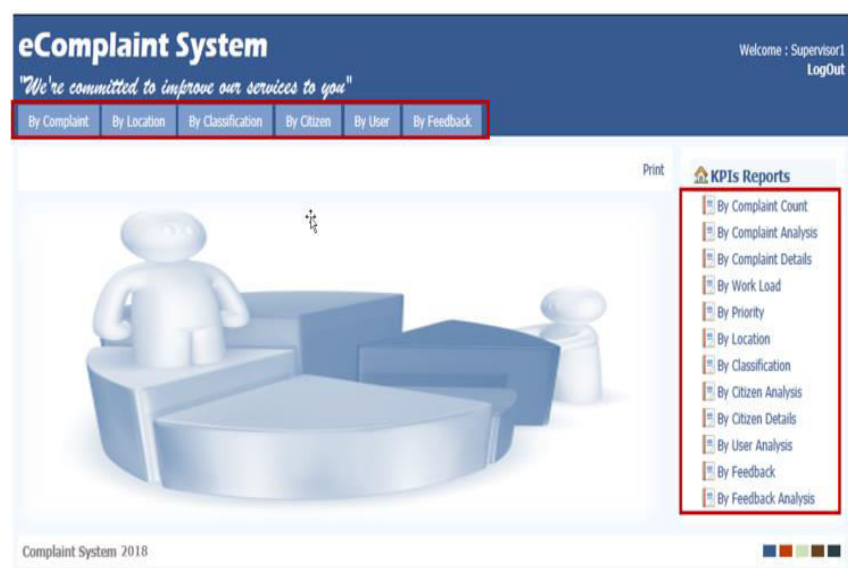

Figure 41: Statistical Reports Main Page (Supervisor Module).

As shown in fig.41. There are 12 reports divided into 6 sections according to shown tabs.

First section is according to 'Complaint' here we can search for complaints by certain date, as shown in figs. (42, 43, 44, $45 \& 46)$ 
As shown in fig.42, in 6/8/2018 there are 20 complaints entered on the system.

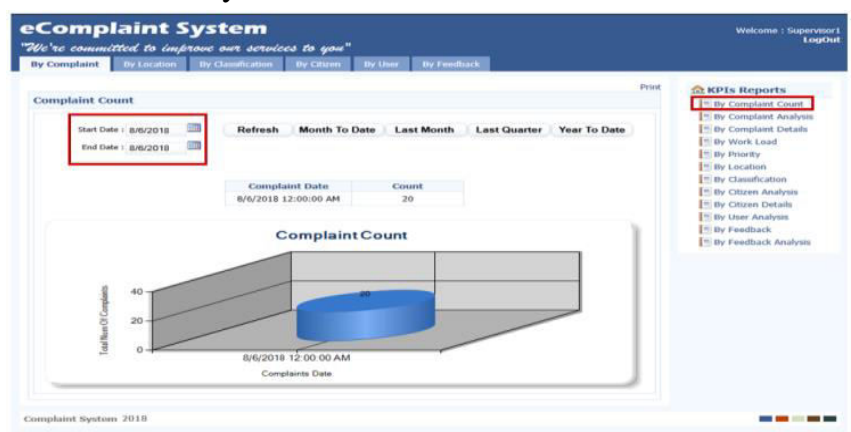

Figure 42: Complaints By one-Day view Report (Supervisor Module).

Fig.43. shows the number of complaints entered from $31 / 7 / 2018$ to $6 / 8 / 2018$.

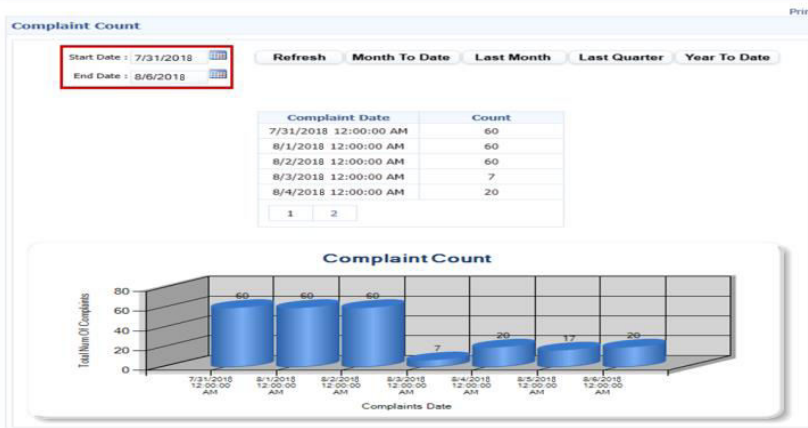

Figure 43:Complaints By certain-duration view Report (Supervisor Module).

Fig.44. shows the number of complaints entered for the last month.

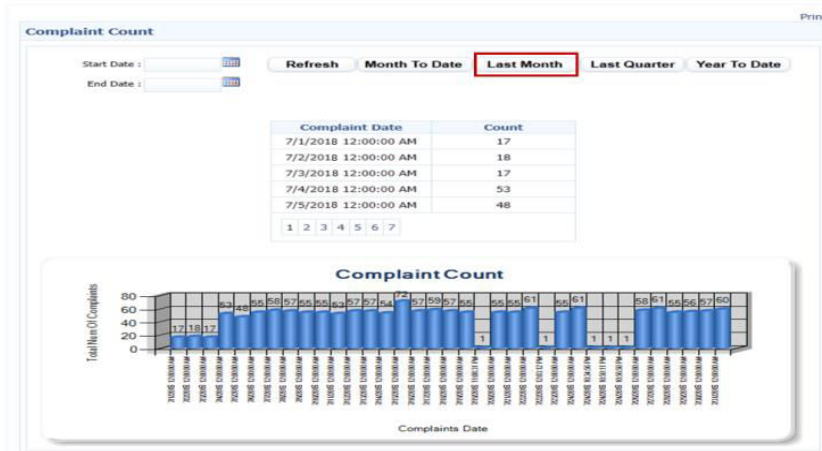

Figure 44: Complaints by Last-Month view Report (Supervisor Module).

Fig.45. shows the number of complaints entered for the last quarter.

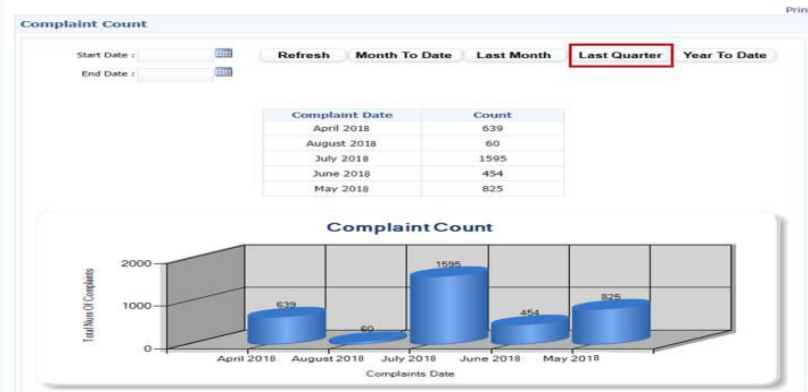

Figure 45: Complaints by Last-Quarter view Report (Supervisor Module).
Fig.46. shows the number of complaints entered for the year 2011.

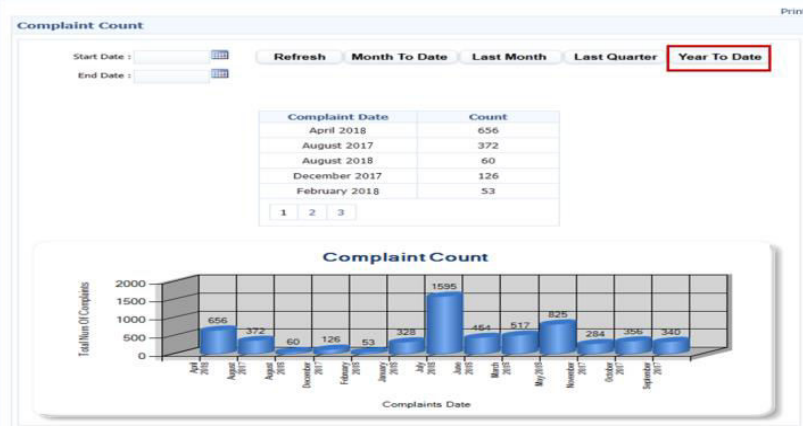

Figure 46: Complaints by Year-to-Date view Report (Supervisor Module).

As shown in fig.47, from 31/10/2017 to $31 / 12 / 2017$ there are 402 complaint case solved and 19 complaint case closed.

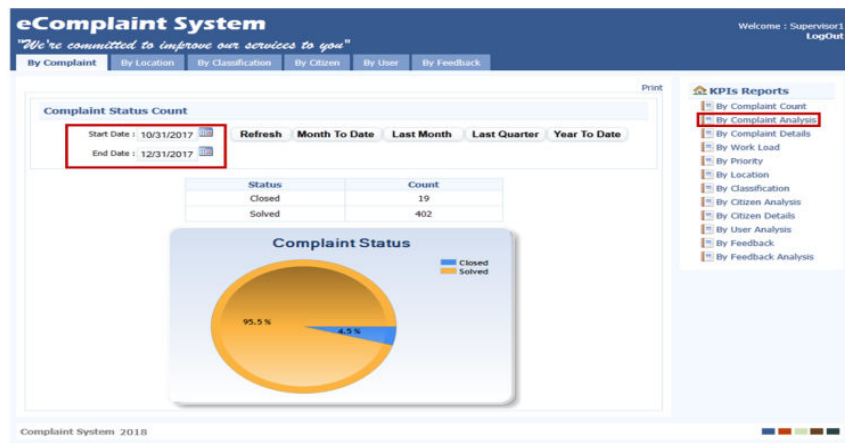

Figure 47: Complaints by Status Count for certain-date Report (Supervisor Module).

As shown in fig.48, in year 2017 there are 4862 solved case, 561 closed case, 1 assigned case and 1 staff assistance case.

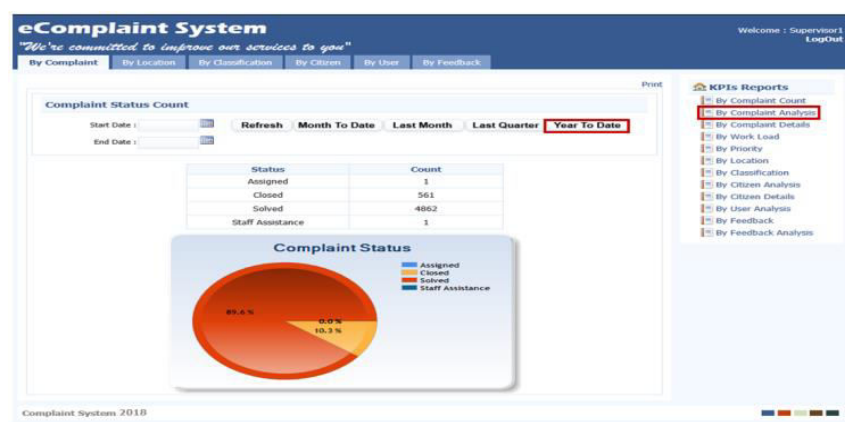

Figure 48: Complaints By Status Count for Year-To-Date Report (Supervisor Module).

Fig.49. shows the work-load report for year 2017 on solving the complaint cases.

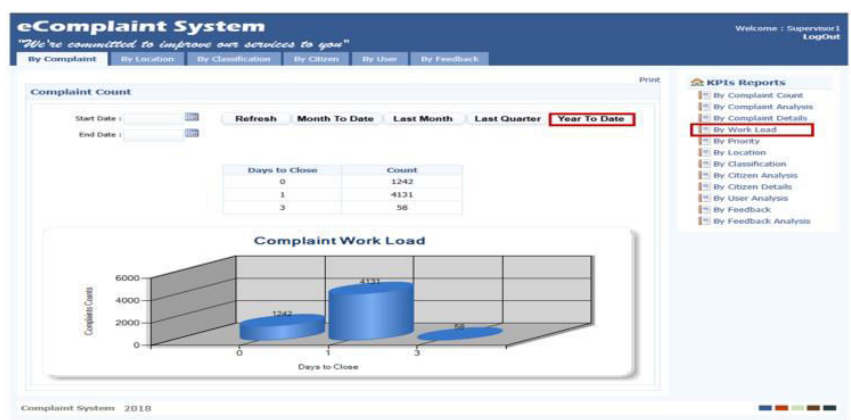

Figure 49: Complaints by Work-Load Report (Supervisor Module). 
Fig.50. shows if the supervisor wants to search for a certain complaint case with full details.

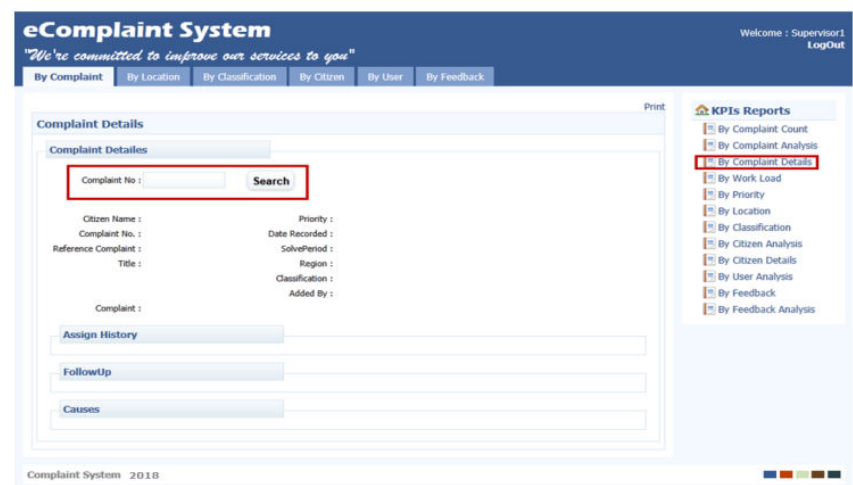

Figure 50: Complaints by Complaint Number Report (Supervisor Module).

As shown in fig.51, the supervisor searches with complaint no. (150720110501).

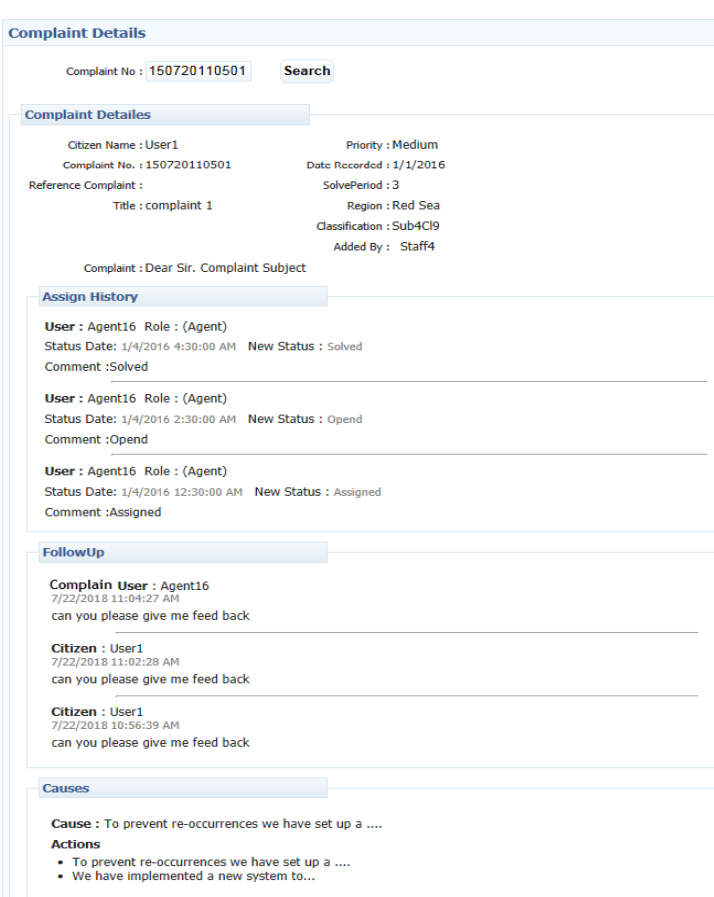

Figure 51: Complaints by Complaint Number details Report (Supervisor Module).

Fig.52. shows that in year 2018 there are 5438 complaints entered on the system as: 1536 high priority, 1238 normal, 1684 medium and 980 low priority complaints.

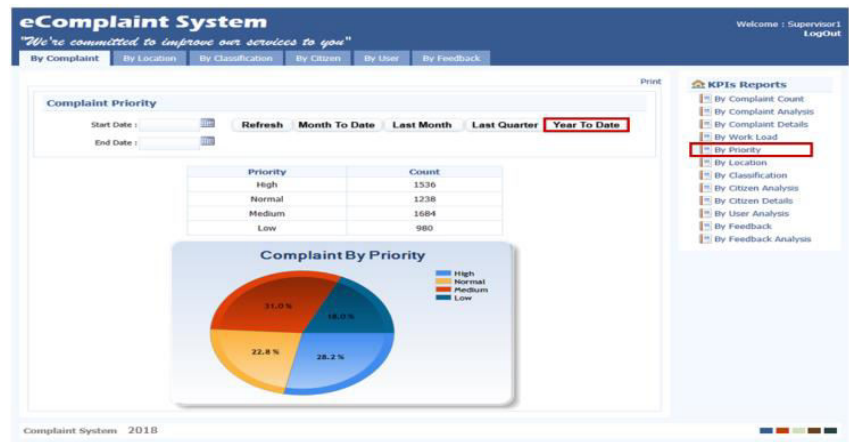

Figure 52: Complaints by Priority Year-To-Date Report (Supervisor Module).
Fig.53. shows the number of complaints entered the system in year 2018 for each Governorate.

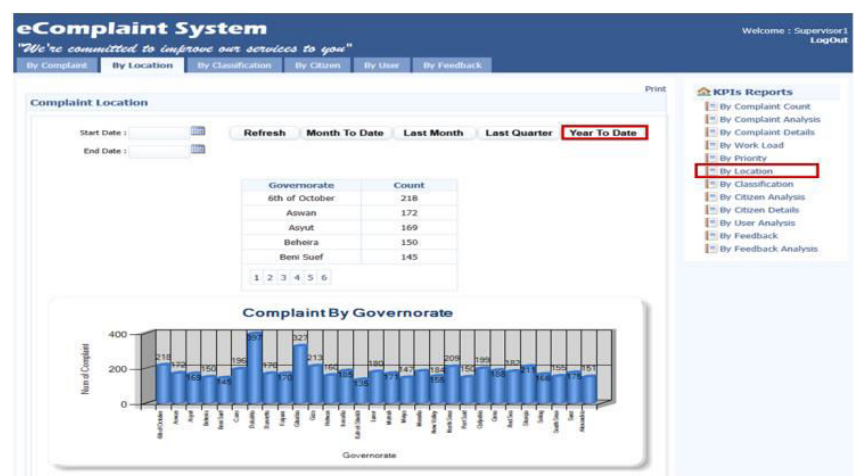

Figure 53: Complaints by Governorate Year-To-Date Report (Supervisor Module).

Fig.54. shows the number of complaints entered the system in year 2018 for each Region.

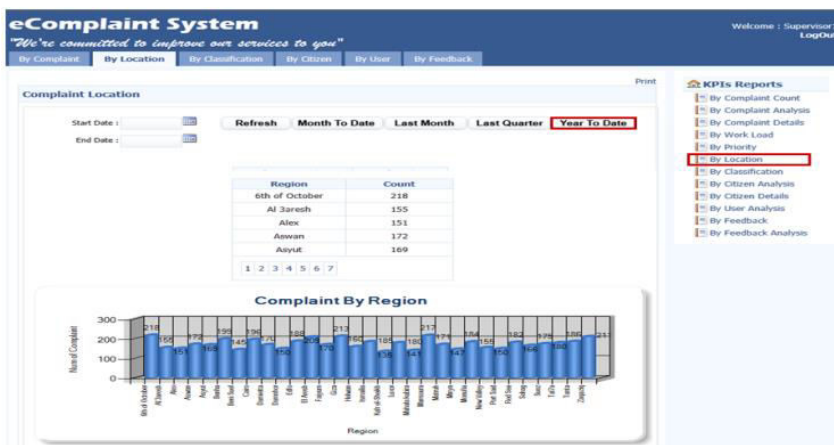

Figure 54: Complaints by Region Year-To-Date Report (Supervisor Module).

Fig.55. shows the number of complaints by classification entered the system in year 2018.

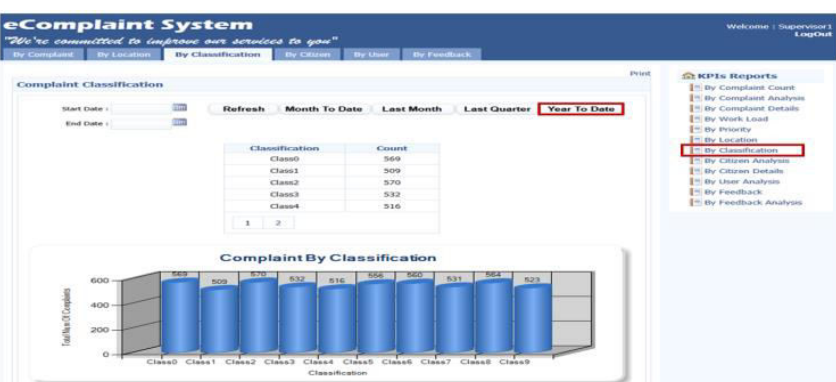

Figure 55: Complaints by Classification Report (Supervisor Module).

Fig.56. shows the number of complaints by subclassification entered the system in 2018.

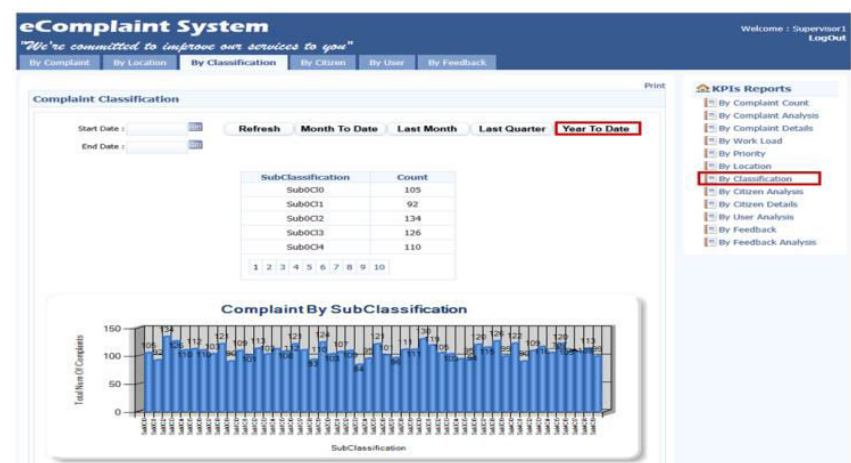

Figure 56: Complaints by SubClassification Report (Supervisor Module). 
Fig.57. shows number of complaints entered by gender and marital status in year 2018.

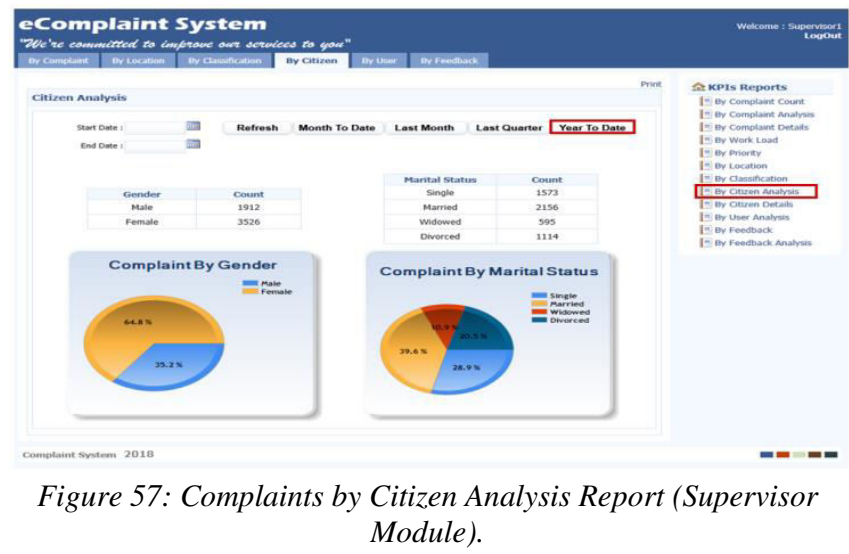

Fig.58. shows the citizen details in year 2018.

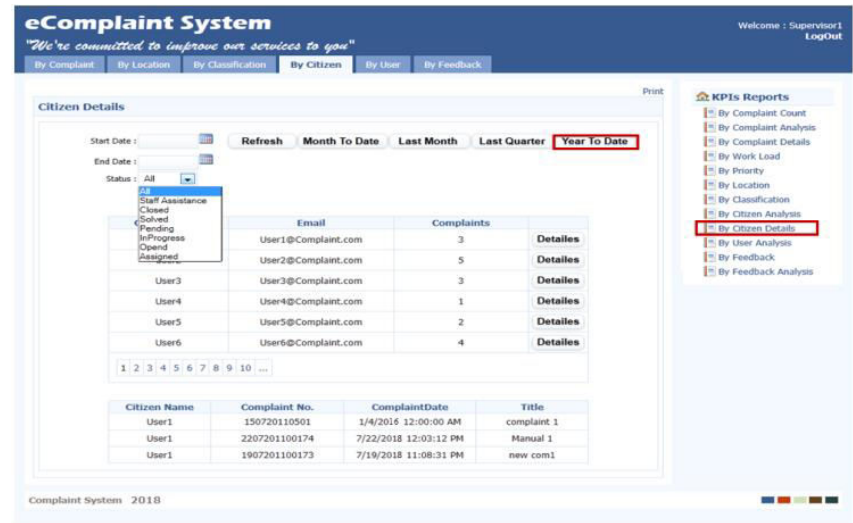

Figure 58: Report for Citizens Details (Supervisor Module).

Fig.59. shows the system user analysis in year 2018.

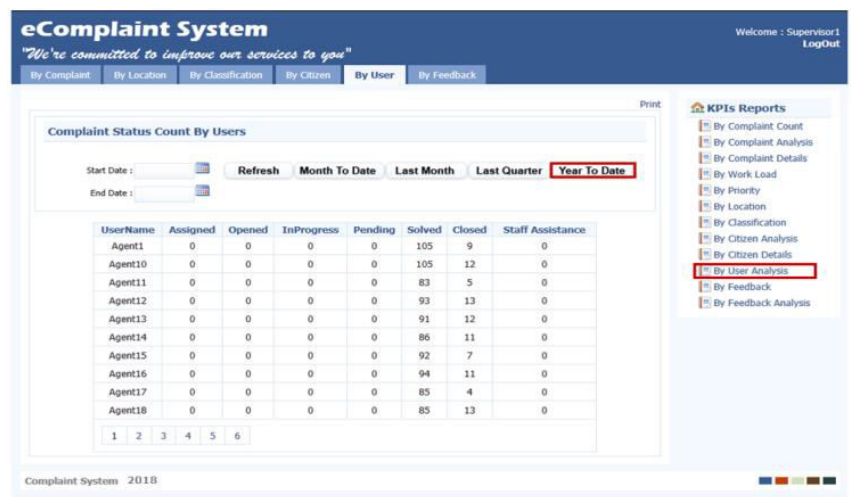

Figure 59: Report for User Analysis (Supervisor Module).

Fig.60. shows the Citizens' feedback on the system.

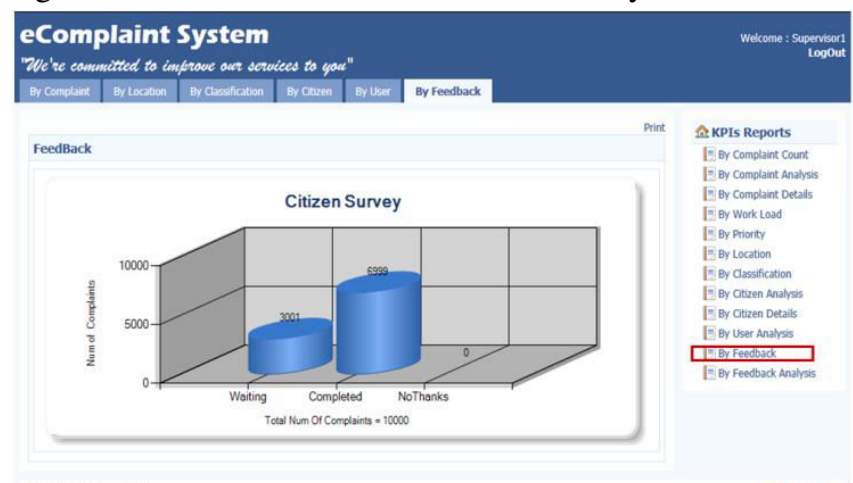

Figure 60: Report for Citizens Feedback (Supervisor Module).
Fig.61. shows the Citizens' survey analysis in year 2018.

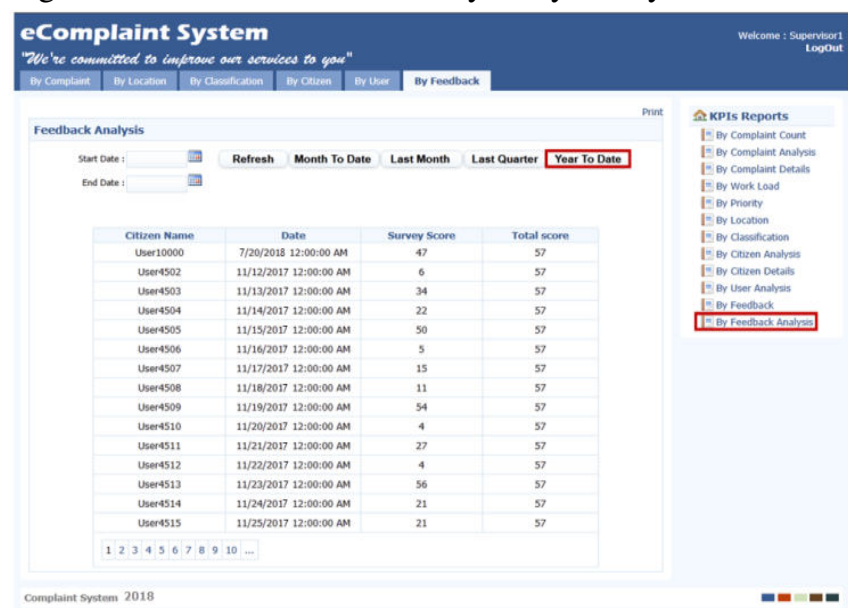

Figure 61: Report for Feedback details (Supervisor Module).

\section{CONCLUSION}

This study innovated a generic approach for the Customer Complaint Management System. The researchers have designed and developed the proposed system from the beginning by using recent technologies which opens chances to any organization regardless of its size to build its own system using simple technology tools.

The researchers presented an overview of the development and implementation of the electronic Customer Complaint Management System (e-CCMS) as a web-service based on Service-Oriented Architecture (SOA). The results obtained from the implementation are encouraging and promising for the development of the proposed model or even more complex systems in the future as the Complaints Management is a complex and critical problem. At the end of this study, the researcher has highlighted how the system works, who are the main users, services and how they can deal with the proposed system. Finally, the researcher believes that the presented model can be helpful in other fields of e-complaining in terms of Citizen Adaption and Citizen Loyalty.

The methodology proved that SOA standards and concepts are feasible to be used in building or transforming e-government solution. It also proved that SOA guarantees flexibility, code free of embedded process rules and solution free from application silos.

\section{REFERENCES}

[1] Afify, E., Hegazy, A., \& El-Sayed, M., (2011). "A Model For Customer Complaint Management System using SOA. ", In Proceedings of the 15th WSEAS International Conference on Computers, World Scientific and Engineering Academy and Society (WSEAS), 291-296.

[2] Afify, E., \& Nasr, M., (2017). "A Proposed Model for a Web-Based Academic Advising System.", International Journal of Advanced Networking and Applications, 9(2), 3345-3361.

[3] Au, N., Buhalis, D., \& Law, R., (2009). "Complaints on the Online Environment - The Case of Hong Kong Hotels.", In W. Höpken, U. Gretzel \& R. Law (Eds.), Information and Communication Technologies in Tourism, 73-85. 
[4] Breitsohl, J., Khammash, M., \& Griffiths, G., (2010). "E-Business Complaint Management: Perceptions and Perspectives of Online Credibility.", Journal of Enterprise Information Management, 23(5), 653-660.

[5] Coussement, K., \& Van den Poel, D., (2008). "Improving Customer Complaint Canagement by Automatic Email Classification Using Linguistic Style Features As Predictors." Decision Support Systems, 44(4), 870-882.

[6] Galitsky, B. A., González, M. P., \& Chesñevar, C. I., (2009). "A Novel Approach for Classifying Customer Complaints Through Graphs Similarities in Argumentative Dialogues.", Decision Support Systems, 46(3), 717-729.

[7] Hansen, T., Wilke, R., \& Zaichkowsky, J., (2010). "Managing Consumer Complaints: Differences and Similarities Among Heterogeneous Retailers.", International Journal of Retail \& Distribution Management, 38(1), 6-23.

[8] Kopparapu, S. K., (2008). "Natural Language Mobile Interface to Register Citizen Complaints.", In TENCON 2008-2008 IEEE Region 10 Conference, 1-6, IEEE.

[9] Najar, A. S., Al-Sukhni, H. A., \& Aghakhani, N., (2010). "The Application of Service-Oriented Architecture in E-complaint System.", In Communication Software and Networks, 2010 (ICCSN'10) Second International Conference, 280-283, IEEE.

[10] Pyon, C. U., Woo, J. Y., \& Park, S. C., (2011). "Service Improvement by Business Process Management Using Customer Complaints in Financial Service Industry.", Expert Systems with Applications, 38(4), 3267-3279.

[11] Razali, R., Halim, K. N. A., \& Jusoff, K. (2011). "Quality Improvement of Services in Unversiti Teknologi Mara Pahang from a Management Perspective.", Management Science and Engineering, 5(1), 71-80.

[12] Sultan, A. B., Abidin, K. Z., \& Abdullah, M. T., (2008). " The Implementation of Agent-based Complaint Management System.", Journal of Computer Science, 8(5), 205-207.

[13] Trappey, A. J., Lee, C. H., Chen, W. P., \& Trappey, C. V., (2010). "A Framework of Customer Complaint Handling System.", In Service Systems and Service Management (ICSSSM), 20107 th International Conference, 1-6, IEEE.

[14] Vos, J. F. J., Huitema, G. B., \& de Lange-Ros, E., (2008). "How Organisations Can Learn From Complaints.", The TQM Journal, 20(1), 8-17.

\section{BIOGRAPHIES AND PHOTOGRAPHS}

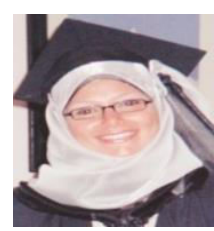

Esraa Abd El-Aziz Abd El-Sadek Afify

Assistant Lecturer in Modern Academy for Computer Science \& Management Technology.

Afify is currently having her Ph.D. in Information Systems from Helwan University.

Afify has M.Sc. in Information Systems from Arab Academy for Science and Technology in 2011 and B.Sc. in Management Information System from Modern Academy for Computer Science \& Management Technology in 2006.

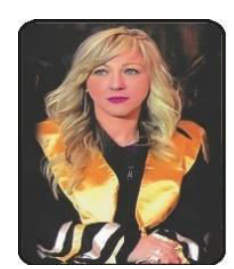

\section{Mona Ahmed Kadry}

Dean Graduate School of Business in Arab Academy for Science, Technology and Maritime Transport

Mona Ahmed Kadry is the dean of the Graduate School of Business at the Arab Academy for Science Technology and Maritime Transport since February 2015.

Prof Kadry is responsible for engaging and supporting more than 2,400 students enrolled in doctoral and master's programs in Business Administration at the Arab Academy for Science Technology and Maritime Transport.

A Professor of Information Systems and Business Research at the Arab Academy for Science Technology and Maritime Transport, her research focuses on Information Systems. She has taught and advised the Arab Academy's undergraduate and graduate students since her 1998 faculty appointment and has served as Associate Dean of College of Computing and Information Technology for International training (2010- July 2011), Program Director for Cardiff Met. University - MBA program (September 2011 January 2015), Associate Dean of College of Post Graduate Studies in Management for International Programs (July 2011- October 2011) and Vice Dean Graduate School of Business at the Arab Academy for Science, Technology and Maritime Transport for Education Affairs (October 2011 January 2015).

Kadry was educated at the Arab Academy for Science Technology and Maritime Transport (B.Sc of Electronics and Communication Engineering, 1997), earned her Ph.D. from the University of West of England (Computer Engineering, 2009).

Kadry is a member of: Administrative Development Association, National Council for Women (committee of Scientific Research) and Committee of Management at Ministry of Culture. Also, she has participated in session at the International Youth conference as well as the National Youth Conference. 